\title{
Chemotherapy induces the cancer-associated fibroblast phenotype, activating paracrine Hedgehog-GLI signalling in breast cancer cells
}

\author{
Maria Peiris-Pagès ${ }^{1,2}$, Federica Sotgia ${ }^{1,2}$ and Michael P. Lisanti ${ }^{1,2}$ \\ 1 The Breakthrough Breast Cancer Research Unit, Institute of Cancer Sciences, University of Manchester, UK \\ 2 The Manchester Centre for Cellular Metabolism (MCCM), Institute of Cancer Sciences, University of Manchester, UK \\ Correspondence to: Federica Sotgia, email: fsotgia@gmail.com \\ Michael Lisanti, email: michaelp.lisanti@gmail.com \\ Keywords: chemotherapy, metabolism, second primary tumours, tumour microenvironment \\ Received: January 10, $2015 \quad$ Accepted: March 26, $2015 \quad$ Published: April 14, 2015
}

This is an open-access article distributed under the terms of the Creative Commons Attribution License, which permits unrestricted use, distribution, and reproduction in any medium, provided the original author and source are credited.

\section{ABSTRACT}

Cancer cells recruit normal cells such as fibroblasts to establish reactive microenvironments. Via metabolic stress, catabolism and inflammation, these cancer-associated fibroblasts set up a synergistic relationship with tumour cells, that contributes to their malignancy and resistance to therapy. Given that chemotherapy is a systemic treatment, the possibility that healthy cell damage affects the metastatic risk or the prospect of developing a second malignancy becomes relevant. Here, we demonstrate that standard chemotherapies phenotypically and metabolically transform stromal fibroblasts into cancer-associated fibroblasts, leading to the emergence of a highly glycolytic, autophagic and pro-inflammatory microenvironment. This catabolic microenvironment, in turn, activates stemness (Sonic hedgehog/GLI signalling), antioxidant response and interferon-mediated signalling, in adjacent breast cancer cells. Thus, we propose a model by which chemotherapy-induced catabolism in healthy fibroblasts constitutes a source of energy-rich nutrients and inflammatory cytokines that would activate stemness in adjacent epithelial cells, possibly triggering new tumorigenic processes. In this context, immune cell recruitment would be also stimulated to further support malignancy.

\section{INTRODUCTION}

Cancer cells are known to be the engine that drives tumour development, although it is now evident that they require help. Endothelial cells, immune cells, adipocytes or fibroblasts are recruited to establish tumorigenic microenvironments, which cooperate with cancer cells to enable and support most of their hallmarks [1]. Stromal fibroblastic cells infiltrate and are induced to differentiate into cancer associated fibroblasts (CAFs) [2], which contribute to the energetics of tumour cells by fuelling them with energy sources such as lactate, ketones, glutamine, fatty acids or cysteine, reinforcing not only their metabolic efficiency and growth but also their survival [3-6] (Figure 1A-1B). Likewise, through lactate-induced extracellular acidification and secretion of inflammatory cytokines and matrix-degrading enzymes,
CAFs enable metastasis and confer resistance to antitumour drugs $[3,7,8]$.

The aim of conventional therapy is to specifically kill the malignant cells within a tumour, although it can also damage normal tissues and the tumour microenvironment. Indeed, secretion of factors associated with inflammation and cancer progression has been detected in therapy-damaged senescent fibroblasts, suggesting that current cancer treatments may contribute to metastasis and de novo tumorigenesis [9]. One of the most severe side-effects of cancer treatment is actually the growth of a second primary tumour, an entirely new malignancy different from metastatic growth. Second primary cancers already account for one in six new cancer diagnoses in the USA and are a significant cause of mortality amongst patients who have been cured of cancer, being the leading cause of death in Hodgkin Lymphoma survivors [10]. Increased risk of developing a 
second malignancy has been reported after treatment with either radiotherapy or chemotherapeutic agents, including alkylating agents, topoisomerase inhibitors and antimetabolites, and it is dose-dependent [10]. Nevertheless, high radiation doses concentrated on a limited field are less tumorigenic than lower doses exposed to a wider area [11]. Hence, considering the systemic nature of chemotherapy, the influence of therapy-damaged non-target cells on the risk of developing a subsequent malignancy becomes significant.

In this study, we test the hypothesis that chemotherapy promotes the same responses in human fibroblasts as their interaction with cancer cells, the socalled catabolic tumour stroma phenotype, which would constitute an ideal environment for a new neoplastic lesion to develop. We provide in vitro evidence of treatmentinduced modifications in fibroblastic cells including the expression of $\alpha \mathrm{SMA}$, a glycolytic switch, an activation of the JNK/AP1, HIF1, TGF $\beta /$ SMAD, STAT3 and NFkB stress-induced pathways, senescence and autophagy, and a greater secretion of the inflammatory cytokine interleukin 6 (IL6). Finally we show the induction of several stemness, antioxidant and immunogenic signalling pathways in breast cancer cells when co-cultured with stromal fibroblasts in response to chemotherapy.

\section{RESULTS}

To study the effects of chemotherapy on stromal cell behaviour, human fibroblasts were treated with different drugs and the induction of the catabolic tumour stroma phenotype was assessed.

A

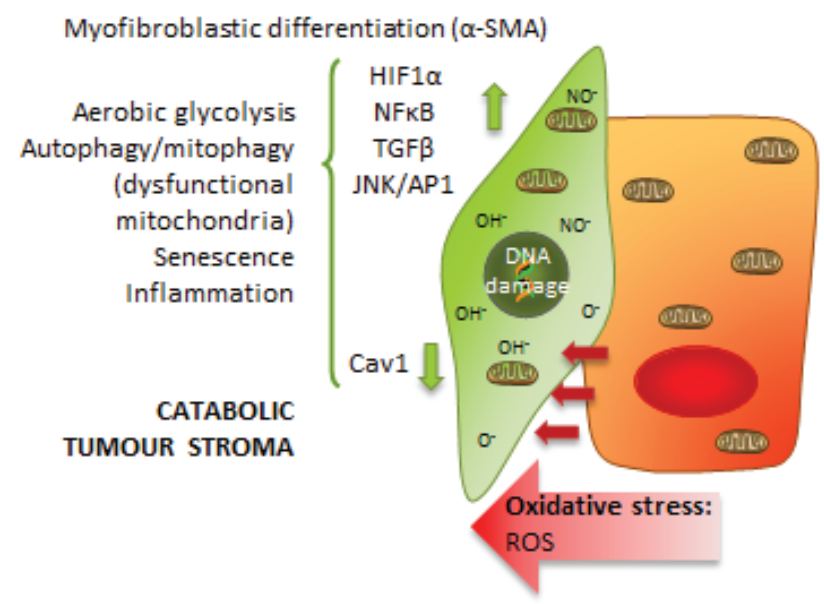

B
We first hypothesised that chemotherapy would increase lactate and ketone production, as we previously showed their tumourigenic and metastatic effects in vivo [12]. As a first screening, L-lactate and $\beta$-hydroxybutyrate $(\beta-\mathrm{HB})$ concentration was measured in hTERT-BJ1 fibroblasts after treatment with 12 different commonly used drugs (Table 1) including azathioprine, carboplatin, cisplatin, cyclophosphamide, doxorubicin, 5-fluorouracil, gemcitabine, methotrexate, 6-mercaptopurine, mitoxantrone, 6-thioguanine and taxol, detecting an increase in their production of L-lactate or $\beta$-HB compared to vehicle (Table S1-S2). Six agents were selected to proceed with the study according to their nature and their potential on increasing L-lactate and $\beta$-HB production at concentrations lower than $1 \mathrm{mM}$. Azathioprine (AZA), an anti-metabolite and carboplatin (CP) and cisplatin (CIS), both alkylating-like agents, were chosen and used for further studies at a concentration of $100 \mu \mathrm{M}$. Likewise, doxorubicin (DOX) and mitoxantrone (MTX), both topoisomerase inhibitors and taxol (TAX), a cytoskeleton drug, were selected at $100 \mathrm{nM}$. All chosen concentrations were sub-lethal and caused a decrease in cell viability lower than $50 \%$ after $72 \mathrm{~h}$ of treatment (Figure S1).

\section{Chemotherapy transforms stromal fibroblasts in highly glycolytic, less metabolically active cells}

High lactate levels suggested a chemotherapyinduced glycolytic switch in stromal fibroblasts. Indeed, L-lactate production and glucose consumption were significantly higher in all treatment conditions compared to vehicle (Figure 2A-2B), and ATP content was lower

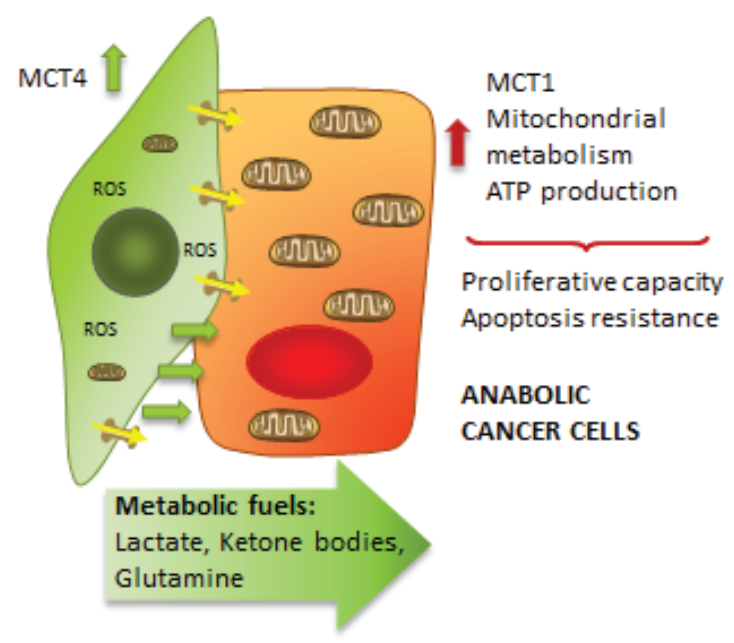

Figure 1: The catabolic tumour stroma phenotype. A. ROS production by rapidly proliferating cancer cells generates oxidative stress to surrounding stromal cells, which induces changes in them such as CAF transformation, activation of HIF1, NFkB, TGF $\beta$ or JNK/AP1 signalling pathways, a switch to aerobic glycolysis and mitochondrial dysfunction, autophagy and senescence and release of inflammatory cytokines: the catabolic tumour stroma phenotype. B. Due to increased glycolysis and autophagy, there is a higher production of energy-rich metabolites such as lactate that are secreted by stromal cells and taken up by cancer cells, which use them to fuel their mitochondrial metabolism and ATP production. 
Table 1: Chemotherapeutic agents used in the current study.

\begin{tabular}{lcc|}
\hline Chemotherapy drug (Abbreviation) & Company (Reference) & Type \\
\hline Azathoiprine (AZA) & Sigma (A4638) & Anti-metabolite \\
\hline Carboplatin (CP) & Sigma (C2538) & Alkylating / alkylating agent \\
\hline Cisplatin (CIS) & Sigma (C2210000) & Alkylating / alkylating agent \\
\hline Cyclophosphamide (CPA) & Sigma (C0768) & Alkylating / alkylating agent \\
\hline Doxorubicin (DOX) & Sigma (D2975000) & Topoisomerase II inhibitor \\
\hline 5-Fluorouracil(5-FU) & Sigma (F6627) & Anti-metabolte \\
\hline Gemcitabine(GC) & Sigma (G6423) & Anti-metabolite \\
\hline Methotrexate(MET) & Sigma (M9929) & Anti-metabolte \\
\hline 6-Mercaptopurine(6-MP) & Sigma (852678) & Anti-metabolite \\
\hline Mitoxantrone (MTX) & Sigma (M6545) & Topoisomerase II inhibitor \\
\hline 6-Thioguanine(6-TG) & Sigma (A4660) & Anti-metabolite \\
\hline Taxol or paclitaxel (TAX) & Sigma (Y0000698) & Cytoskeleton drug \\
\hline
\end{tabular}

after azathioprine, doxorubicin, mitoxantrone and taxol treatments (Figure 2C). The extracellular acidification rate (ECAR) was subsequently measured using an XF96 Extracellular Flux Analyzer (Figures 3A-3C and S2A) and glycolysis, glycolytic capacity and glycolytic reserve were calculated after addition of glucose, oligomycin and 2-DG into the media. All drugs significantly increased glycolytic capacity and most of them augmented the basal glycolytic rate and glycolytic reserve (Figure 3D). Oxygen consumption rate (OCR) and ECAR were also measured in media containing glucose to plot the OCR versus ECAR graph, which indicates the metabolic state of the cell (Figure S2B). All agents notably induced a switch from a more aerobic and metabolically active phenotype towards a more glycolytic, less metabolically active phenotype (Figure 3E-3G).

Increased ECAR indicated that the lactate produced by fibroblasts upon treatment was being secreted. Indeed, the expression of MCT4, the transporter that mediates monocarboxylate efflux, was perceptibly up-regulated in chemotherapy-treated hTERT-BJ1 compared to vehicle, as observed by immunofluorescence (Figure 4). Thus, chemotherapy stimulates fibroblasts to consume more glucose and produce more lactate, which is released

Figure 2: Chemotherapy increases L-lactate production and glucose consumption and reduces ATP content of hTERT-BJ1 fibroblasts. A. Chemotherapy increases L-lactate production. L-lactate secretion by hTERTBJ1 fibroblasts treated with chemotherapy for 48 and $72 \mathrm{~h}$ normalised to vehicle-treated cells. All drugs increased lactate production. Mean \pm SEM. B. Chemotherapy increases glucose consumption. Glucose consumption by hTERT-BJ1 cells treated with chemotherapy for $72 \mathrm{~h}$ normalised to vehicle-treated cells. All drugs augmented glucose uptake. Mean \pm SEM. C. Chemotherapy reduces ATP content. ATP content in hTERT-BJ1 cells treated with chemotherapy for 24,48 and $72 \mathrm{~h}$ normalised to vehicle-treated cells. Azathioprine, doxorubicin, mitoxantrone and taxol decreased the ATP levels at some of the assessed time points. Mean $\pm \mathrm{SEM}$. via enhanced MCT4 expression, hence increasing extracellular acidification. According to the less efficient ATP production during glycolysis than in complete
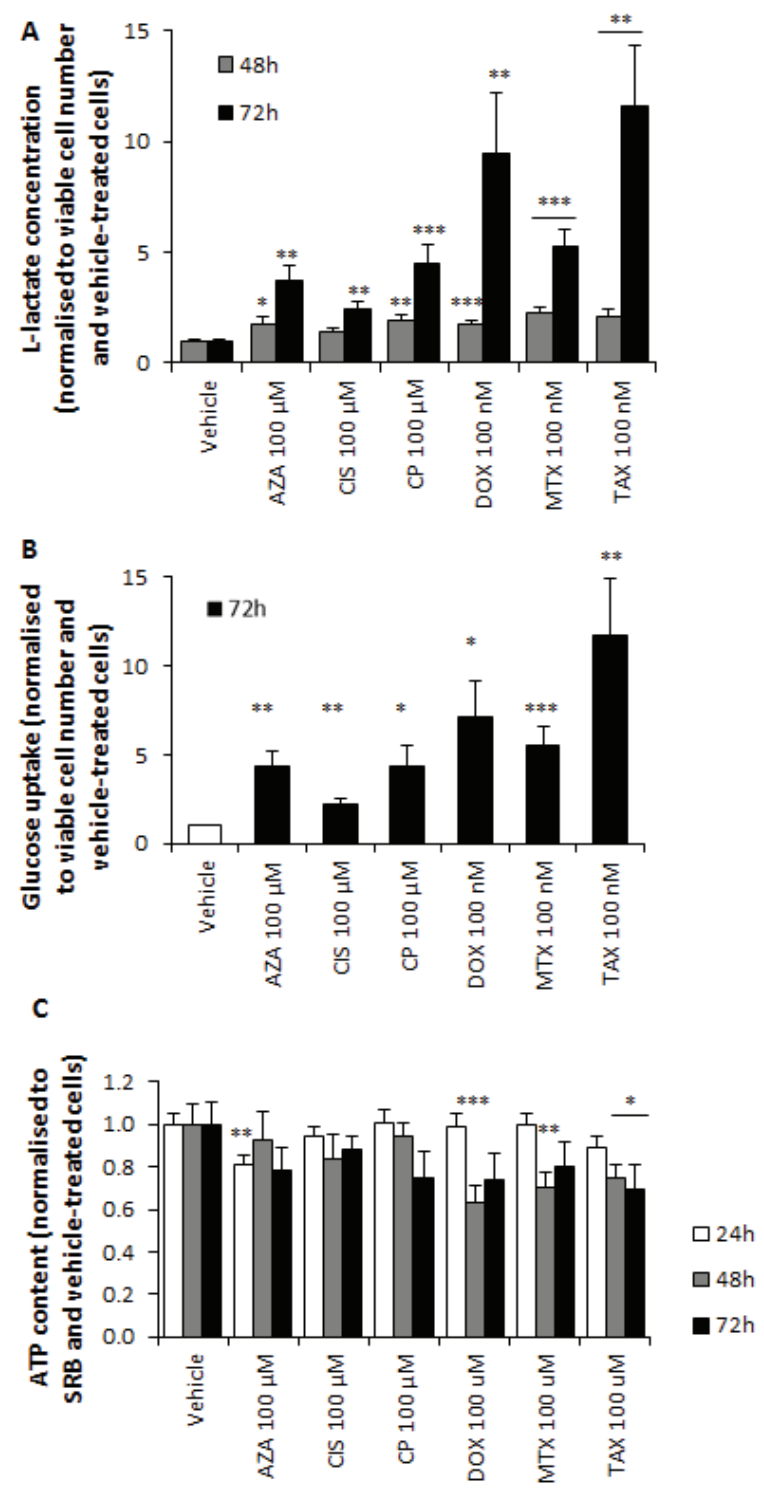

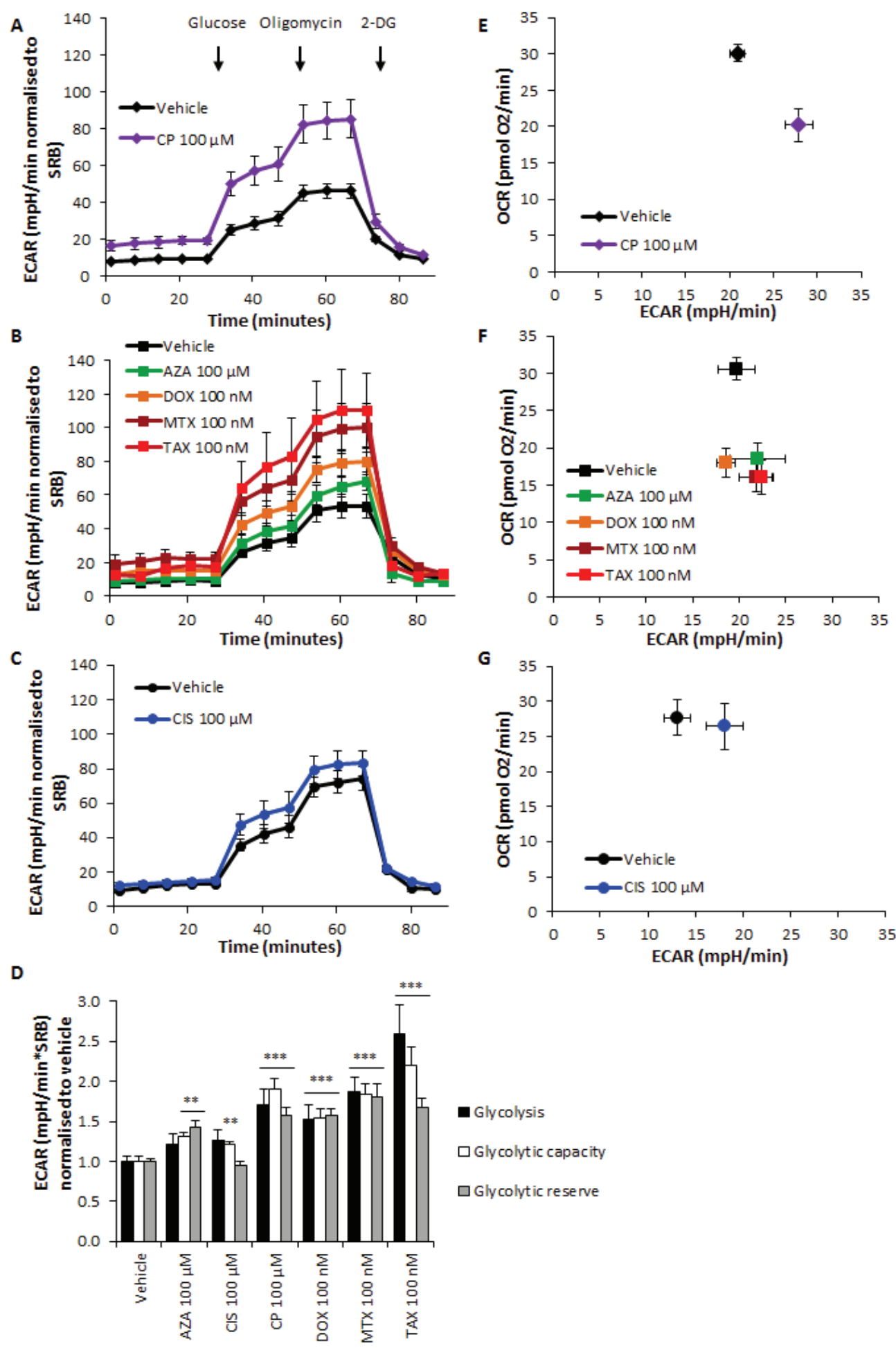

Figure 3: Chemotherapy increases glycolytic function of hTERT-BJ1 fibroblasts and transforms them into less metabolically efficient cells. A. hTERT-BJ1 fibroblasts were treated for $72 \mathrm{~h}$ with carboplatin, B. azathioprine, doxorubicin, mitoxantrone, taxol and $\mathbf{C}$. cisplatin before the extracellular efflux assay was performed. All drugs increased the ECAR of hTERT-BJ1 cells throughout the experiment compared to vehicle treatments. Mean \pm SEM. D. Glycolysis, glycolytic capacity and glycolytic reserve measurements of chemotherapy-treated hTERT-BJ1 fibroblasts relative to vehicle-treated cells. All drugs significantly increased glycolytic capacity, and most of them also augmented the glycolytic reserve of hTERT-BJ1 fibroblasts (except cisplatin). Likewise, basal glycolytic rate was enhanced in carboplatin, doxorubicin, mitoxantrone and taxol treatments. Mean \pm SEM. E. hTERT-BJ1 fibroblasts were treated for $72 \mathrm{~h}$ with carboplatin, F. azathioprine, doxorubicin, mitoxantrone, taxol and $\mathbf{G}$. cisplatin before the extracellular efflux assay in the presence of glucose was performed, and the OCR versus ECAR graph was represented. All drugs induced a shift towards a less metabolically active phenotype in hTERT-BJ1 cells. Mean \pm SEM. 
Table 2: Cignal Lenti reporter assay and GFPvectors used in this study and cell line utilised for transduction for each of them.

\begin{tabular}{|c|c|c|c|c|}
\hline Vector & & necopoeia (reference) & Cell line & Selection \\
\hline GFP & & EX-EGFP-Lv151 & MCF7 & $\mathrm{G} 4181 \mathrm{mg} / \mathrm{ml}$ \\
\hline $\begin{array}{l}\text { Cignal Lenti reporter } \\
\text { assay (luc) }\end{array}$ & $\begin{array}{c}\text { Qiagen } \\
\text { (reference) }\end{array}$ & Pathway & Cell line & Selection \\
\hline AP1(luc) & CLS-011L & JNK/AP1-regulated signal transduction & hTERT-BJ1 & Puromycin $2 \mu \mathrm{g} / \mathrm{ml}$ \\
\hline ARE(luc) & CLS-2020L & $\begin{array}{l}\text { Nrf2-and Nrf1-mediated antioxidant } \\
\text { response }\end{array}$ & hTERT-BJ 1 and MCF7-GFP & Puromycin $2 \mu \mathrm{g} / \mathrm{ml}$ \\
\hline GAS(luc) & CLS-009L & $\begin{array}{l}\text { Interferon gamma-induced signal } \\
\text { transduction }\end{array}$ & hTERT-BJ 1 and MCF7-GFP & Puromycin $2 \mu \mathrm{g} / \mathrm{ml}$ \\
\hline GLI(luc) & CLS-3030L & Hedgehog signaling pathway & MCF7-GFP & Puromycin $2 \mu \mathrm{g} / \mathrm{ml}$ \\
\hline HIF(luc) & CLS-007L & HIF-mediated hypoxia signaling & hTERT-BJ1 & Puromycin $2 \mu \mathrm{g} / \mathrm{ml}$ \\
\hline ISRE(luc) & CLS-008 & $\begin{array}{l}\text { Type I interferon-induced signal } \\
\text { transduction }\end{array}$ & hTERT-BJ 1 and MCF7-GFP & Puromycin $2 \mu \mathrm{g} / \mathrm{ml}$ \\
\hline NFkB(luc) & CLS-013L & NFkB-regulated signal transduction & hTERT-BJ1 & Puromycin $2 \mu \mathrm{g} / \mathrm{ml}$ \\
\hline SMAD(luc) & CLS-017L & TGFB-induced signal transduction & hTERT-BJ 1 and MCF7-GFP & Puromycin $2 \mu \mathrm{g} / \mathrm{ml}$ \\
\hline STAT3(luc) & CLS-6028L & Transcriptional activity of STAT3 & hTERT-BJ 1 and MCF7-GFP & Puromycin $2 \mu \mathrm{g} / \mathrm{ml}$ \\
\hline TCF/LEF(luc) & CLS-018L & Wnt signal transduction & MCF7-GFP & Puromycin $2 \mu \mathrm{g} / \mathrm{ml}$ \\
\hline
\end{tabular}
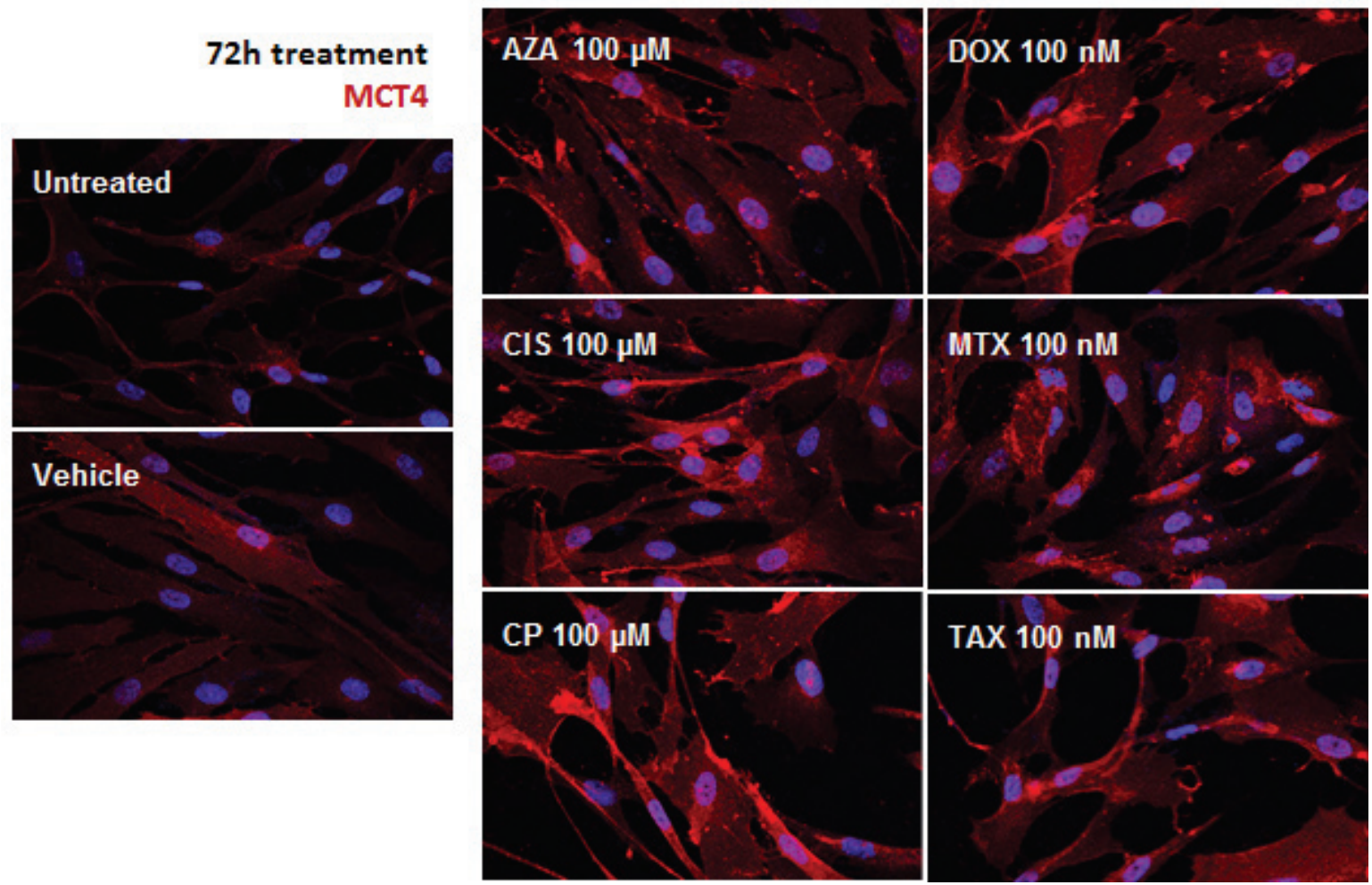

Figure 4: MCT4 expression is up-regulated in response to chemotherapy. Representative pictures of hTERT-BJ1 fibroblasts treated for $72 \mathrm{~h}$ and immunostained for MCT4 (red). Nuclei were counterstained with DAPI (blue). Untreated and vehicle-treated hTERTBJ1 images are also shown. 

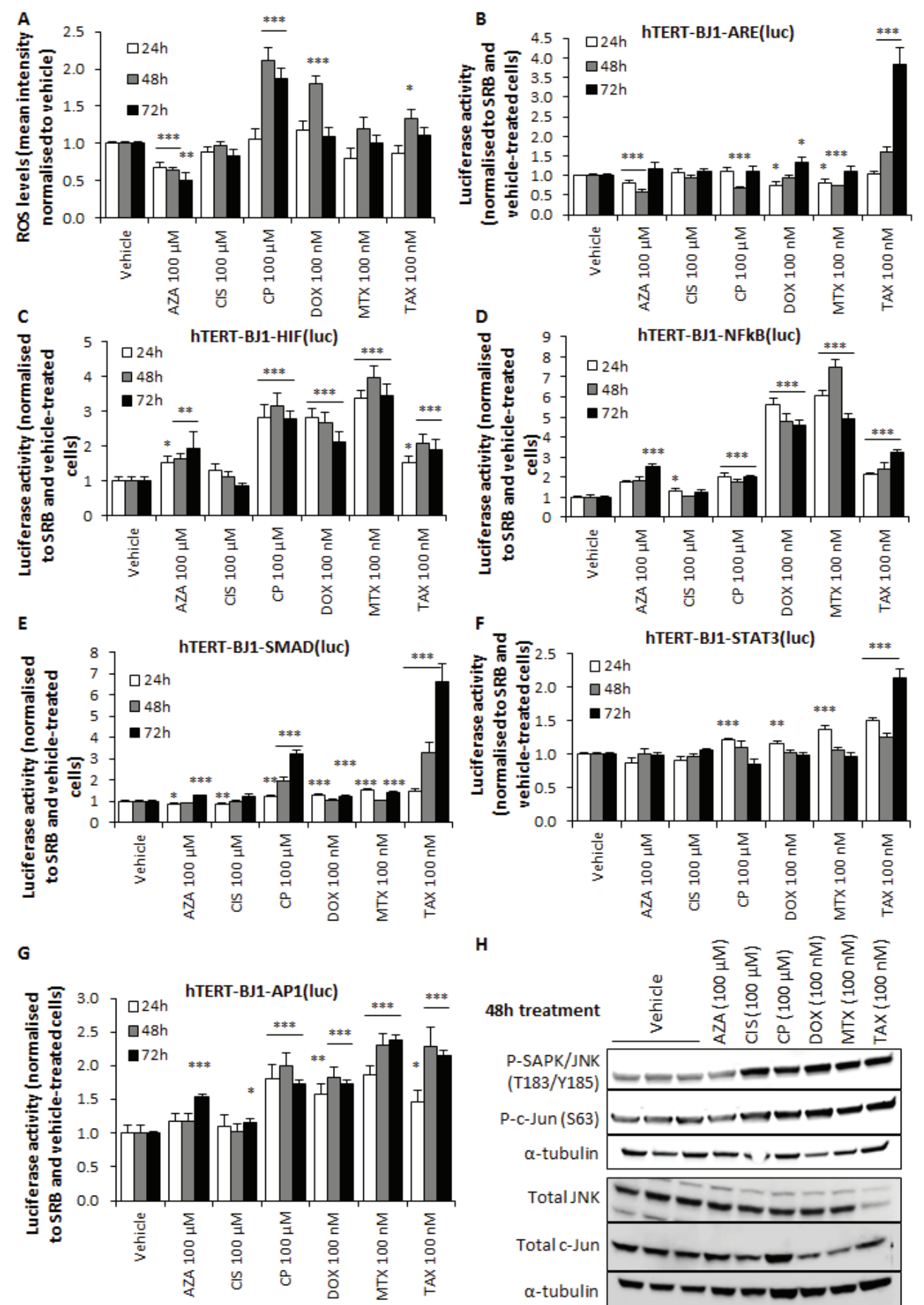

H

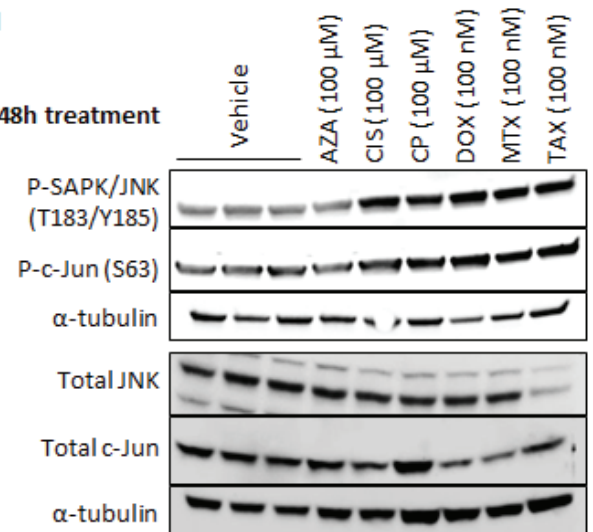

Figure 5: Chemotherapy induces oxidative stress and activates stress signalling pathways in hTERT-BJ1 fibroblasts. A. Intracellular ROS levels of hTERT-BJ1 fibroblasts treated with chemotherapy for 24, 48 and $72 \mathrm{~h}$ normalised to vehicle-treated cells. At $48 \mathrm{~h}$ of chemotherapeutic treatment, carboplatin, doxorubicin and taxol significantly induced the production of ROS. Mean \pm SEM. B. ARE-dependent signalling pathway activation after treatment with chemotherapy for 24,48 and $72 \mathrm{~h}$ normalised to SRB and vehicletreated cells. Only doxorubicin and taxol were able to significantly activate Nrf1 and Nrf2-mediated antioxidant response at late time points. Mean \pm SEM. C. Significant activation of HIF D. NFkB, E. SMAD, F. STAT3 and G. AP1 signalling pathway in response to chemotherapy after 24, 48 and $72 \mathrm{~h}$ normalised to SRB and vehicle-treated cells. All drugs were able to activate NFkB and AP1. All drugs except cisplatin could also increase HIF and SMAD activation. Likewise, all drugs except azathioprine and cisplatin significantly stimulated STAT3 $24 \mathrm{~h}$ after treatment. Mean \pm SEM. H. Chemotherapy-induced increase in the phosphorylation levels of SAPK/JNK and c-Jun in hTERT-BJ1 fibroblasts as measured by Western blotting after $48 \mathrm{~h}$ of treatment with all drugs except azathioprine. Total JNK and c-Jun protein levels did not show substantial differences. Only carboplatin intensified total c-Jun protein expression levels. 
oxidative phosphorylation, the ATP content is minor.

\section{Chemotherapy promotes oxidative stress and stress-induced signalling pathways in stromal fibroblasts}

We next sought to determine the intracellular ROS levels of chemotherapy-treated hTERT-BJ1 fibroblasts, as chemotherapy has been shown to cause oxidative stress in cancer cells and healthy tissues [13, 14]. Carboplatin, doxorubicin and taxol treatments enhanced ROS production, whereas cisplatin and mitoxantrone did not modify ROS levels and azathioprine reduced them (Figure 5A). To evaluate whether high oxidative stress was due to an antioxidant response deficiency, we generated hTERT-BJ1-ARE(luc) reporter cells, which were exposed to chemotherapy and assessed for luciferase activity. Taxol and doxorubicin induced a significant activation of luciferase activity at late time points. Other drugs did not increase or even significantly reduced ARE-dependent response, including carboplatin, which produced the highest ROS levels (Figure 5B). Thus, some drugs were able to induce oxidative stress in stromal fibroblasts at the chosen concentrations, but either failed to elicit antioxidant response or that response was slow, implying a lack of a strong antioxidant response as one of the reasons behind the increase in ROS production.

Oxidative stress in the stroma, which is generally caused by cancer cells at the onset of their synergy, promotes CAF transformation and HIF1, NFkB, JNK, STAT3 and TGF $\beta$ activation in the stromal compartment $[6,15,16]$. Thus, we next assessed the activation of these signalling pathways. Five reporter hTERT-BJ1 cell lines were generated (Table 2), exposed to chemotherapy, and luciferase activity was determined. All drugs significantly amplified NFkB and AP1 signalling (Figure 5D, 5G). Likewise, HIF, SMAD and STAT3 signalling was increased by most agents (Figure 5C, 5E-5F). Finally, upstream of AP1, the phosphorylation levels of SAPK/ JNK and c-Jun were also up-regulated after all drug treatments except azathioprine relative to vehicle-treated fibroblasts, as measured by immunoblotting, whereas total JNK and c-Jun protein levels did not show substantial differences, indicating an activation of the whole JNK/ AP1 pathway in chemotherapy-treated hTERT-BJ1 fibroblasts. Carboplatin also intensified total c-Jun protein expression levels (Figure 5H).

\section{Chemotherapy triggers autophagy, senescence, and IL6 secretion in stromal fibroblasts}

Autophagy and senescence are known to be a common response to DNA-damaging agents such as chemotherapy $[17,18]$. Autophagy is a process by which lipid degradation is induced and therefore ketone bodies are generated. Thus, we decided to assess whether chemotherapy can also induce autophagy and ketogenesis in these cells. Stromal fibroblasts were exposed to chemotherapy and subsequently stained for autophagic vacuole production, which was significantly enhanced by all drugs (Figure 6A). We next measured the levels of ketones in the media of chemotherapy-treated fibroblasts, and in line with our first screening we found that all drugs induced $\beta$-HB secretion (Figure $6 \mathrm{~B}$ ). To determine senescence levels after chemotherapy treatment, hTERTBJ1 fibroblasts were assessed for senescence-associated $\beta$-galactosidase (SA- $\beta$-gal) activity, which appeared to be significantly greater in all drug treatments except mitoxantrone (Figure 6C). Alternatively, expression of p53 and p21, known regulators of cellular senescence, was also assessed by immunoblotting. Most drugs showed p53 and p21 over-expression (Figure 6D). Collectively, these results indicate higher autophagy and senescence in hTERT-BJ1 fibroblasts upon treatment.

One of the features of senescence is the tumourpromoting senescence-associated secretory phenotype (SASP), which occurs in response to treatment-induced DNA damage in normal and tumour cells [19, 20] and contains inflammatory cytokines, which can further aggravate chemotherapy-related inflammation. We therefore decided to determine whether chemotherapy would induce secretion of inflammatory cytokines by screening the media of hTERT-BJ1 cells treated with either doxorubicin or vehicle using a Cytokine Antibody Array. IL6 was the most up-regulated cytokine in doxorubicin -treated fibroblasts relative to vehicle (Figure $\mathrm{S} 3 \mathrm{~A})$. Indeed, amongst SASP-secreted cytokines there is IL6, which is also present in the media of fibroblasts and cancer cells in co-culture [21]. Doxorubicin, mitoxantrone and taxol significantly increased the secretion of IL6 in hTERT-BJ1 fibroblasts, as confirmed by ELISA, whereas azathioprine decreased it (Figure 6E).

\section{Chemotherapy induces myofibroblastic transformation}

Myofibroblasts or CAFs are abundant components of the tumour microenvironment and mostly accountable for the development of fibrosis, a common side effect of cancer therapy. CAFs are characterised by the expression of $\alpha$-smooth muscle actin ( $\alpha$ SMA) [22]. Therefore, we determined $\alpha$ SMA expression on lysates of chemotherapytreated hTERT-BJ1 fibroblasts, observing an upregulation of $\alpha$ SMA by most drugs (Figure 6D). Thus, chemotherapy can trigger transformation of fibroblasts into myofibroblasts. 
A

C
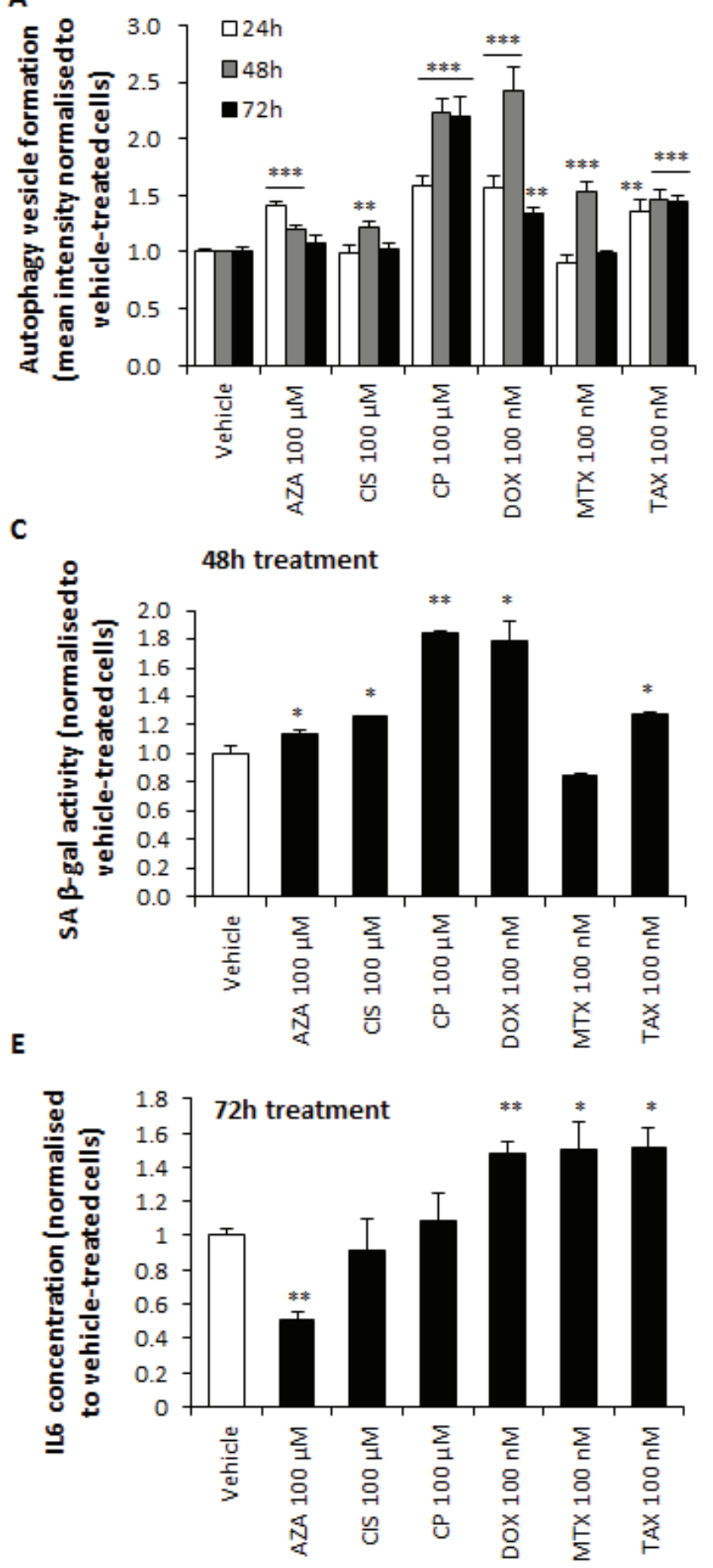

B

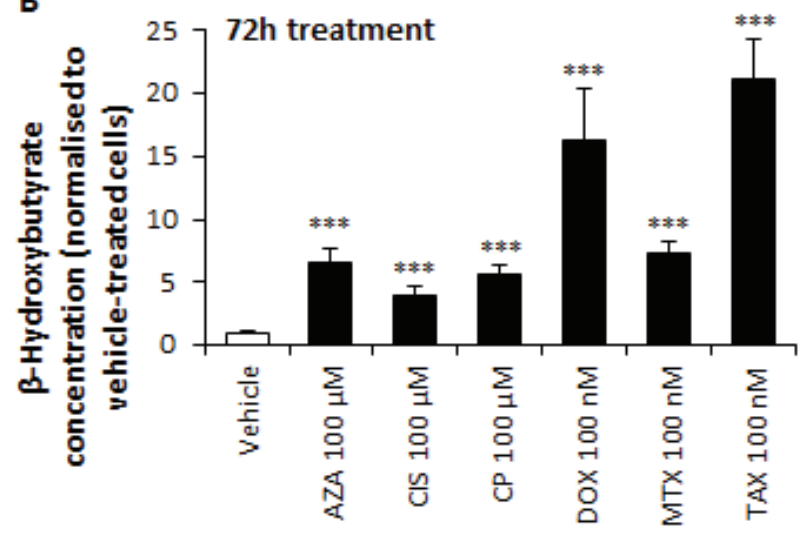

D 48h treatment

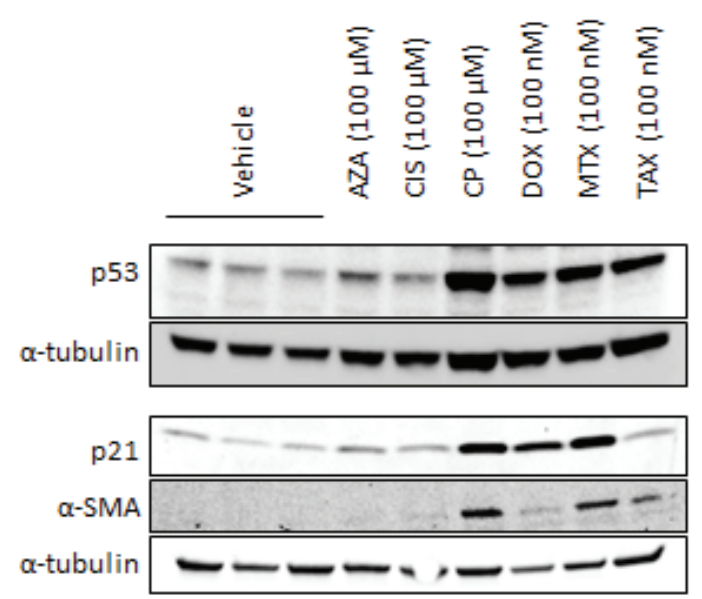

Figure 6: Chemotherapy induces autophagy, senescence, CAF transformation and IL6 secretion in hTERT-BJ1 fibroblasts. A. Autophagy vesicle staining in hTERT-BJ1 fibroblasts after 24, 48 and $72 \mathrm{~h}$ of treatment with chemotherapy normalised to vehicle-treated cells. All drugs significantly increased autophagy at all or some of the assessed time points. Mean \pm SEM. B. $\beta$-HB secretion by hTERT-BJ1 fibroblasts after $72 \mathrm{~h}$ of chemotherapy treatment normalised to vehicle. All drugs significantly increased $\beta$-HB concentration. Mean \pm SEM. C. Quantification of SA- $\beta$-gal activity as measured by FDG-fluorescein staining in hTERT-BJ1 fibroblasts after $48 \mathrm{~h}$ of chemotherapy treatment normalised to vehicle-treated cells. All drugs except mitoxantrone significantly increased the levels of SA- $\beta$-gal. Mean \pm SEM. D. Chemotherapy-induced up-regulation of p53, p21 and $\alpha$-SMA in hTERT-BJ1 fibroblasts as measured by Western blotting. All drugs except azathioprine and cisplatin clearly increased p53 and $\alpha$-SMA expression. Expression of p21 was also found up-regulated in all drugs except cisplatin and taxol. E. Interleukin 6 levels present in media of hTERT-BJ1 fibroblasts treated for 72 $\mathrm{h}$ with chemotherapy as measured by ELISA. Doxorubicin, mitoxantrone and taxol significantly increased IL6 secretion. Mean $\pm \operatorname{SEM}$. 
A

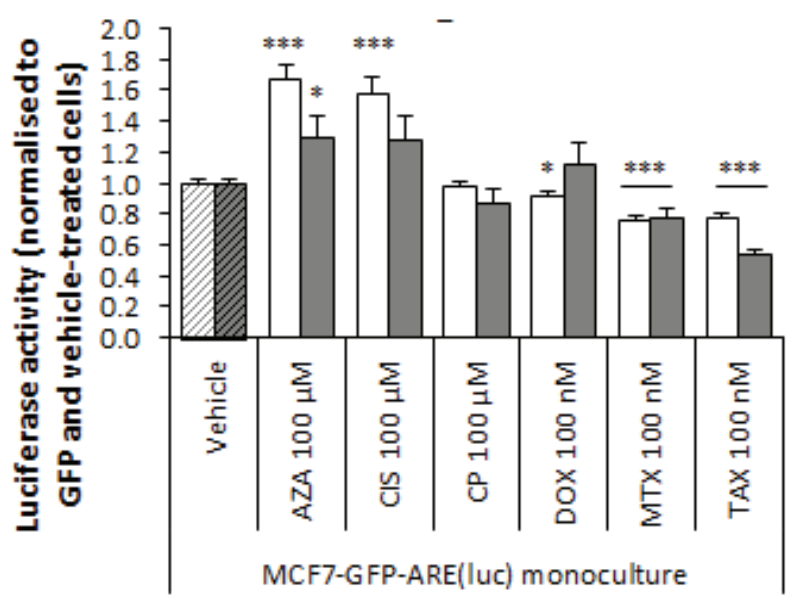

C

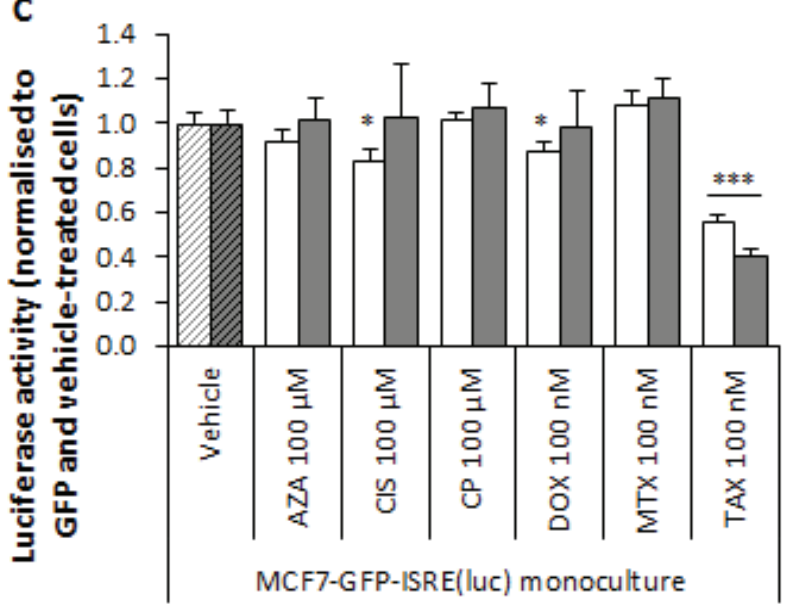

$\mathbf{E}$

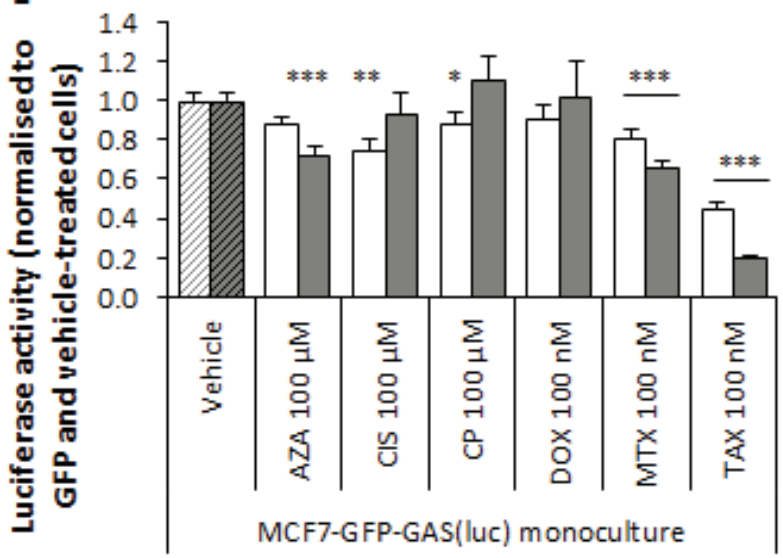

B

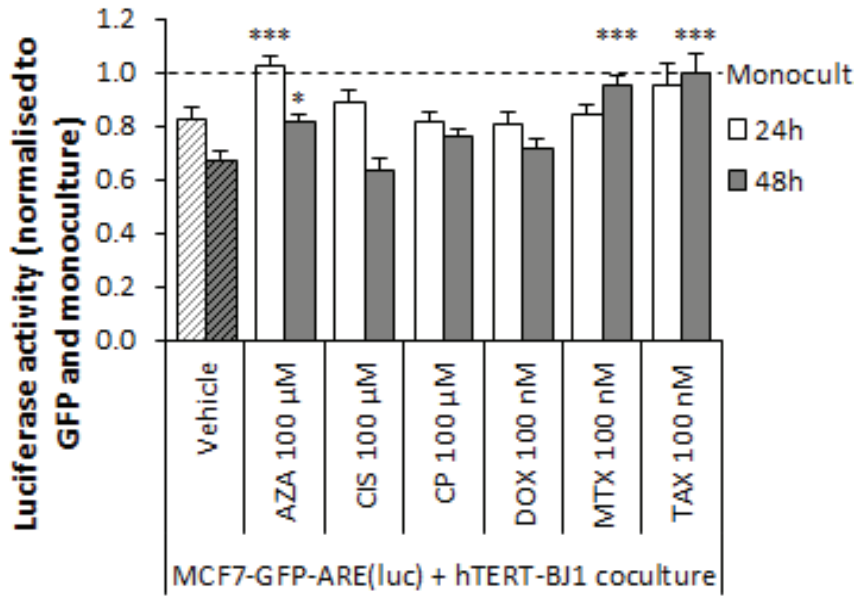

D

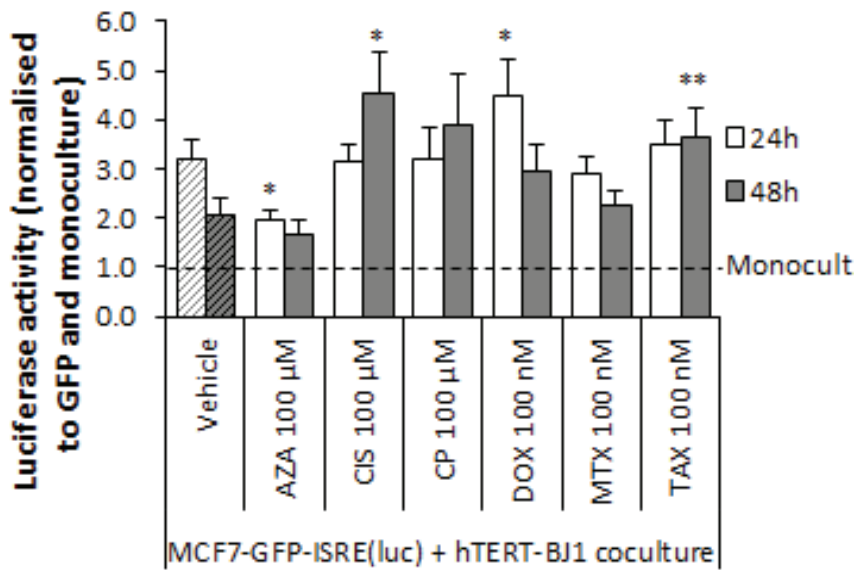

$\mathbf{F}$

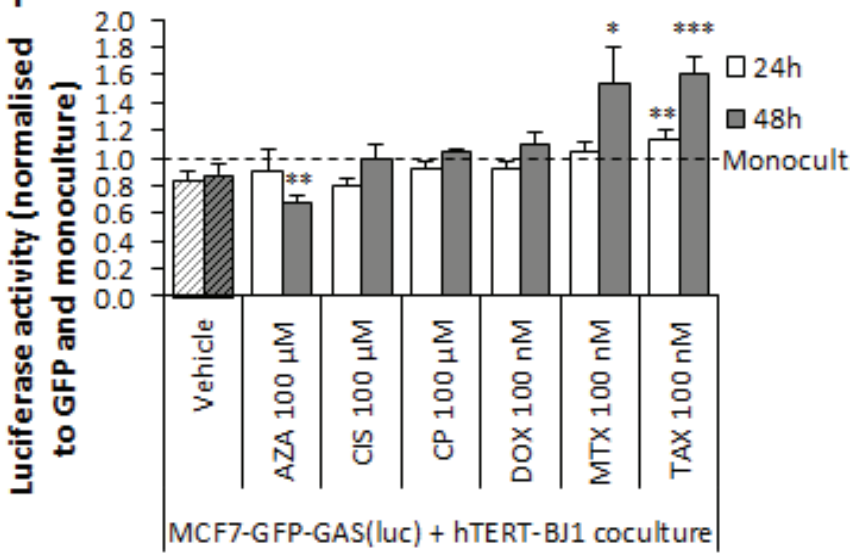

Figure 7: In response to chemotherapy, hTERT-BJ1 fibroblasts trigger antioxidant and immune response in MCF7GFP cells. Left panels. Chemotherapy effects on A. ARE, C. ISRE, and E. GAS signalling pathways in MCF7-GFP cells in monoculture after 24 and $48 \mathrm{~h}$ normalised to GFP fluorescence and vehicle-treated cells. Azathioprine and cisplatin showed increased antioxidant response in the monocultures, and doxorubicin, mitoxantrone and taxol, decreased. Most drugs inhibited interferon-mediated signalling in the MCF7-GFP monocultures. Mean \pm SEM. Right panels. Chemotherapy effects on B. ARE, D. ISRE and F. GAS signalling pathways in MCF7-GFP cells in co-culture after 24 and $48 \mathrm{~h}$ normalised to GFP fluorescence and cells in monoculture. ARE signal was significantly activated in azathioprine, mitoxantrone and taxol co-cultures compared to vehicle-treated co-cultures. ISRE signalling was increased in cisplatin, doxorubicin and taxol co-cultures compared to vehicle-treated co-cultures. Finally, GAS signal was significantly activated in mitoxantrone and taxol co-cultures compared to vehicle-treated co-cultures. Mean $\pm \mathrm{SEM}$. 


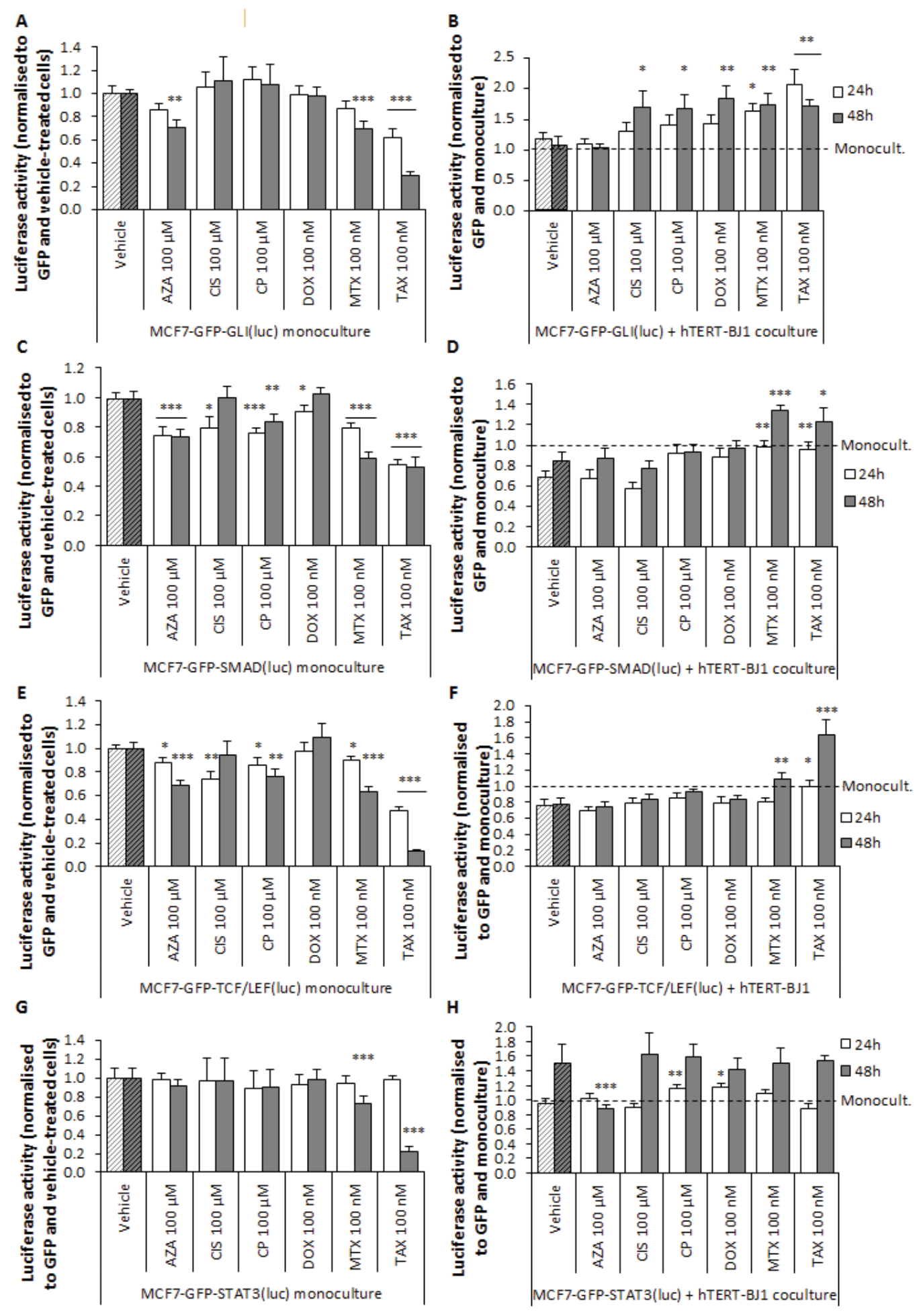

Figure 8: In response to chemotherapy, hTERT-BJ1 fibroblasts induce stemness-related pathways in MCF7-GFP cells. Left panels. Chemotherapy effects on A. GLI, C. SMAD, E. TCF/LEF and G. STAT3 signalling pathways in MCF7-GFP cells in monoculture after 24 and $48 \mathrm{~h}$ normalised to GFP fluorescence and vehicle-treated cells. Most drugs were able to inhibit GLI, SMAD and TCF/LEF signalling in the MCF7-GFP monocultures. Mitoxantrone and taxol also inhibited STAT3 in the monocultures. Mean \pm SEM. Right panels. Chemotherapy effects on B. GLI, D. SMAD, F.TCF/LEF and H. STAT3 signalling pathways in MCF7-GFP cells in co-culture after 24 and $48 \mathrm{~h}$ normalised to GFP fluorescence and cells in monoculture. All drugs except azathioprine activated GLI signalling pathway in the co-cultures compared to vehicle-treated co-cultures. SMAD and TCF/LEF signal was significantly activated also in mitoxantrone and taxol co-cultures compared to vehicle-treated co-cultures. Finally, carboplatin and doxorubicin were able to activate STAT3 signalling in the co-cultures. Mean \pm SEM. 


\section{Upon treatment, stromal fibroblasts stimulate stemness, antioxidant and immune response in breast cancer cells}

Using our co-culture system in a range of reporter cells, we pursued to identify the mechanism by which stromal cells promote chemoresistance, prompt metastasis or even de novo tumorigenesis. We hypothesised that therapy-induced stromal IL6 secretion would stimulate STAT3 in neighbouring cancer cells. Likewise, we assessed the effects of stromal cells on antioxidant (ARE), immune response (ISRE, GAS), or stem cell signalling (GLI, TCF/LEF, SMAD) in cancer cells when co-cultured with fibroblasts upon treatment. Therefore, several reporter MCF7-GFP cell lines were generated (Table 2), and cultured either as monolayers or cocultured with fibroblasts, treated with chemotherapy, and assessed for luciferase activity. We first evaluated AREdependent signalling pathway. Azathioprine and cisplatin significantly increased luciferase signal in MCF7GFP-ARE(luc) monocultures, whereas doxorubicin, mitoxantrone and taxol significantly decreased it (Figure 7A). ARE signalling was inhibited when fibroblasts were present in the culture. However, azathioprine, mitoxantrone and taxol co-culture treatments did not inhibit luciferase activity compared to vehicle, showing a reactivation of ARE signalling (Figure 7B).

Immune response is thought to be supressed in the body after anti-cancer treatment. Indeed, the drugs used in this study are also used as immunosuppressants. Therefore, we assessed interferon-mediated signalling, which was significantly inhibited by most drugs in MCF7 (Figure 7C, 7E) and hTERT-BJ1 monocultures (Figure S3B-S3C). Nevertheless, interaction with hTERT-BJ1 remarkably enhanced ISRE activation in MCF7 cells. Cisplatin, doxorubicin and taxol treatments further increased ISRE signalling in the co-cultures compared to vehicle, and azathioprine significantly decreased it (Figure 7D). The presence of hTERT-BJ1 in the culture reduced GAS signalling, yet carboplatin and doxorubicin did not inhibit GAS signalling and luciferase signal in mitoxantrone and taxol co-culture treatments was significantly higher than in the vehicle (Figure 7F). Thus, cancer cells in contact with stromal fibroblasts are able to elicit interferon-mediated signalling in response to chemotherapy.

Finally, we determined the activation of stemnessrelated pathways in MCF7 cancer cells in synergy with stromal fibroblasts after chemotherapeutic exposure. Most drugs did not have an effect or inhibited all assessed pathways in the cancer cell monolayers (Figure 8A, 8C, $8 \mathrm{E}$ and $8 \mathrm{G})$. In interaction with hTERT-BJ1 fibroblasts, Sonic hedgehog (Shh)/GLI signalling was not modified, TGF $\beta / S M A D$ and Wnt/TCF/LEF signalling pathways were decreased, and STAT3 signalling was activated at 48 h. However, in co-cultures, all drugs except azathioprine remarkably stimulated GLI signalling compared to vehicle, in MCF7 cancer cells (Figure 8B). Likewise, carboplatin and doxorubicin did not inhibit SMAD signalling as observed in the vehicle and luciferase activity of mitoxantrone and taxol co-culture treatments was significantly augmented. Similarly, carboplatin did not inhibit Wnt signalling, and mitoxantrone and taxol were able to stimulate TCF/LEF signalling compared to the vehicle (Figure 8D and 8F). Finally, carboplatin and doxorubicin reinforced STAT3 signalling after $24 \mathrm{~h}$, whereas azathioprine inhibited it (Figure 8H).

In summary, chemotherapy inhibits most studied signalling pathways in MCF7 cancer cells. In contact with hTERT-BJ1 fibroblasts, though, MCF7 cancer cells establish a crosstalk with stromal cells as assessed by activation or inhibition of these pathways. That interaction, however, is altered upon treatment and stromal fibroblasts are able to stimulate antioxidant and immune response, and trigger various signalling pathways associated with tumour proliferation, survival and stemness in MCF7 cancer cells, providing new insights from which treatment failure and chemotherapy-induced tumorigenesis can be further investigated.

\section{DISCUSSION}

\section{Chemotherapy promotes the catabolic tumour stroma phenotype}

In this study we show for the first time the induction of a clear metabolic stress in stromal fibroblasts that favours glycolysis and lactate production to the detriment of mitochondrial metabolism in response to chemotherapy, phenotype previously defined as one of the hallmarks of the catabolic tumour stroma. Previous results in breast cancer imply that lactate secreted by stromal fibroblasts can be utilised as a mitochondrial fuel by the surrounding cancer cells $[12,23]$, and enables chemoresistance due to extracellular acidification [24]. Moreover, lactate administration increases the number of metastasis in vivo and stimulates migration [12] and expression of stemnessrelated genes in breast cancer cells in vitro. These gene signatures can in turn predict recurrence and metastasis in breast cancer [25].

Our results demonstrate that chemotherapy can stimulate HIF, NFkB, SMAD, STAT3 and JNK/AP1 stress-linked signalling pathways, and are consistent with previous studies showing activation of these signalling pathways due to oxidative stress by anticancer therapies also in healthy cells $[6,13,32]$. Oxidative stress in the stroma is generally caused by cancer cells at the onset of their metabolic synergy $[6,26]$ and promotes CAF transformation in the stromal compartment and invasiveness in breast cancer cells [15]. HIF1, NFkB, 
JNK, STAT3 and TGF $\beta$ activation in the stroma occurs with increased catabolism, which in turn can promote cancer proliferation $[14,16,27-30]$ and can cause immunosuppression and angiogenesis, making cancer more invasive [31].

Exposure to chemotherapy also induced the transformation of stromal fibroblasts into myofibroblasts, another feature of the catabolic tumour stroma. It has been previously shown that the presence of fibrotic lesions actually enhances the risk of developing cancer [33], pointing at $\mathrm{CAF}$ transformation as a feature that can lead to de novo tumorigenesis.

In addition we detect increased autophagy, ketone production and senescence in chemotherapy-treated stromal fibroblasts. Autophagic hTERT-BJ1 fibroblasts, generated by over-expression of autophagy promoters, such as cathepsin B, and senescent hTERT-BJ1 fibroblasts, generated via over-expression of CDK inhibitors, such as $\mathrm{p} 21$, are able to enhance tumour growth and metastasis when co-injected with breast cancer cells in vivo [34, 35]. Moreover, ketogenic fibroblasts stimulate mitochondrial biogenesis in the neighbouring cancer cells [36], and upregulation in ketogenic enzyme expression has recently been correlated with therapy failure [37]. Finally, systemic ketogenesis and high stromal senescence are commonly associated with tumorigenesis [38, 39]. Likewise a chronic inflammatory microenvironment also contributes to all tumorigenic stages such as the induction of neoplasticrelated mutations, resistance to apoptosis or metastasis $[40,41]$. The IL6/STAT3 pathway is particularly important in inflammation-related tumorigenesis [42].

A

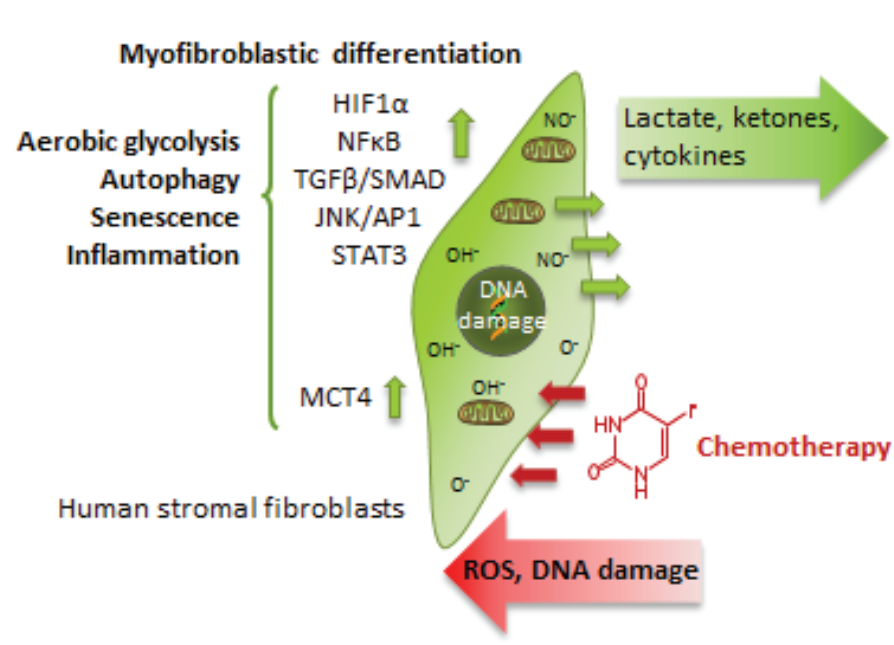

Cancer cells induce NFkB signalling in tumour-associated macrophages (TAMs), triggering their IL6 secretion, which in turn stimulates the neoplastic proliferation via STAT3 activation [43]. Consistent with that, and with the fact that chemotherapy is associated with up-regulation of inflammation markers and stress response genes in healthy tissues [44, 45], we observed that chemotherapydamaged fibroblasts trigger NFkB and other stressinduced pathways and promote the secretion of IL6, energy-rich metabolites and possibly other ligands, which have the potential to succour cancer cells in their battle for survival, in their purpose to metastasise, or even through which partially-transformed epithelial cells may be more susceptible to become fully malignant, giving rise to a new cancer.

\section{Stromal metabolic stress enhances stemness, antioxidant and immune response in cancer cells. Is the catabolic stroma able to persuade partially transformed cells into becoming fully malignant?}

We finally sought to identify the mechanism by which stromal cells may promote chemoresistance, metastasis or de novo tumorigenesis using our co-culture system. Strikingly, Shh signalling was predominantly activated in breast cancer cells in contact with stromal cells in response to chemotherapy, as well as Wnt, STAT3 and TGF $\beta$ pathways, which are involved in progenitor and stem cell renewal, metabolism [46], metastasis and chemoresistance [47]. Abnormal activation of Shh, Wnt

B

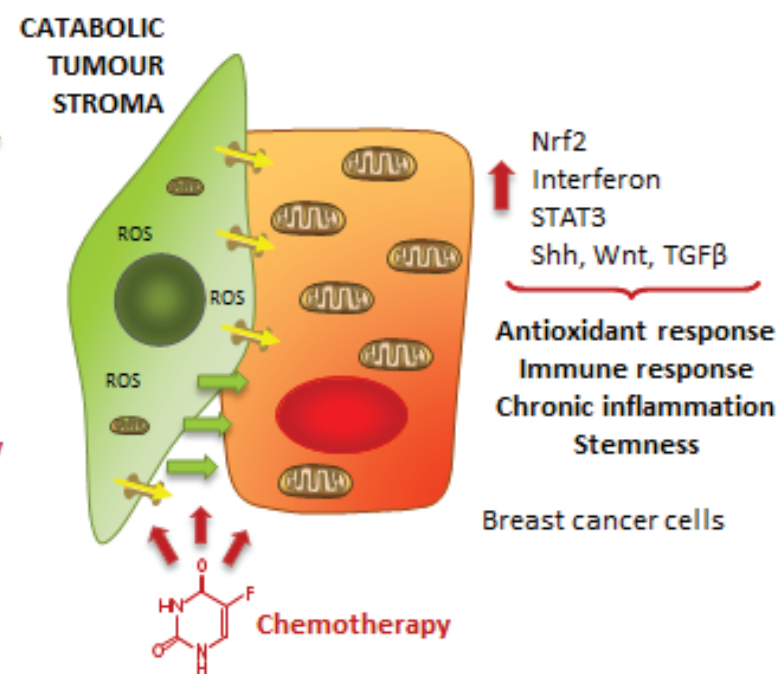

Figure 9: Chemotherapy induces the catabolic tumour stroma phenotype, which in turn activates antioxidant response, immune response and stemness in cancer cells. A. Chemotherapy-induced DNA damage generate activation of HIF1, NFkB, TGF $\beta$, STAT3 and JNK/AP1 signalling pathways in stromal cells, which stimulates their differentiation into CAFs, a switch to aerobic glycolysis and mitochondrial dysfunction, autophagy and senescence, release of inflammation cytokines and inhibition of interferon-mediated signalling. B. In contact with these catabolic fibroblasts, cancer cells react to chemotherapy by activating antioxidant and immune response signalling, and by activating stemness. 
and TGF $\beta$ signalling is found in many types of cancer $[48,49]$. In fact, de novo mutational activation of Shh pathway by itself can result in cancer [49], and it is also involved in the synergy of cancer and stromal cells, as stromal hh production stimulates neoplastic proliferation and metastasis [50], and tumour-secreted hh ligands in turn induce CAF transformation generating a tumourpromoting microenvironment [51]. Moreover, these pathways are involved in cellular metabolism. When STAT3 is found in the mitochondria enhances oxidative phosphorylation, encouraging the growth of cancer cells when over-expressed [52]. Wnt signalling also increments oxidative phosphorylation in breast cancer cells [53]. Interestingly, conditioned media from primary tumour fibroblasts or co-cultures with fibroblasts reduces chemotherapy efficacy due to improved mitochondrial function in the cancer cells [3], implying that upon therapy stromal fibroblasts may support cancer cells in their struggle for survival via stimulation of these stemness pathways.

In the present study, we also observe that in response to chemotherapy, Nrf1 and Nrf2-mediated signalling is reactivated in MCF7 cancer cells in contact with stromal fibroblasts. Several studies show constitutive up-regulation of Nrf2 in many cancers, which provides a growth advantage for cancer cells by protecting them from anticancer agents $[54,55]$.

Finally, in response to chemotherapy we detect that cancer cells in contact with stromal fibroblasts are able to elicit interferon-mediated signalling. In fact, exposure to chemotherapy in vivo induces recruitment of monocytic cells and macrophages to tumours, which is associated with cancer cell survival and poor therapy responsiveness $[56,57]$. TAMs gather in the tumour microenvironment in response to cytokines such as Csf1, a STAT1 target gene. Indeed, Stat1-null animals show reduced macrophage infiltration [58], and in agreement with our findings, breast cancer microarray analyses indicate that high mRNA expression levels of Stat1 and its target genes belonging to the interferon-mediated signalling correlate with poor drug response and infiltration of immune cells, in particular TAMs [59]. Hence, the response to a same stimulus is cell context-dependent and different microenvironment components participate in the development of malignancy and chemoresistance. Likewise, not all drugs induce an identical behavioural pattern. The diverse nature of the anti-tumour agents, and the doses and the length of the treatments selected for the study may account for these differences.

So far, very little is known about the role of healthy cells in the emergence of therapy-related malignancies. Initiation of tumorigenesis by accumulation of genetic changes is not sufficient for a tumour to develop, and requires the emergence of a reactive microenvironment, which via metabolic alterations and inflammation, contributes to the progression of the tumour and leads to treatment failure [1]. Therefore, cancer initiates in the tumour cell but gradually and systemically disseminates driving catabolism in healthy tissues. The mechanisms by which stromal metabolic stress controls the evolution of malignancy or even the susceptibility of a premalignant cell to become fully malignant are not understood. One piece of evidence shows that pre-treatment of tumourfree mice with a single dose of doxorubicin is sufficient to stimulate lung carcinoma cell engraftment and elevate the mitogenic activity of the serum of treated animals [9]. Here, we propose a new model by which upon treatment, stromal cells acquire a catabolic state that leads to an autophagic, nutrient-rich, senescent, pro-inflammatory microenvironment (Figure 9A), the ideal niche to encourage carcinogenesis by stimulating stemness in therapy-damaged pre-malignant epithelial cells and by increasing inflammation and immune cell infiltration, which in turn could further promote malignancy in these cells (Figure 9B). Nevertheless, given that successfully treating the primary cancer should always be a priority, targeting stromal cells in combination with conventional chemotherapy may help disrupting these ill-behaved microenvironments, improving treatment efficacy and avoiding future malignancies.

\section{MATERIALS AND METHODS}

\section{Cell culture}

Human foreskin fibroblasts immortalised with the human telomerase reverse transcriptase (hTERT-BJ1), and MCF7 breast cancer cells were purchased from ATCC and maintained in DMEM (D6546, Sigma) supplemented with 10\% fetal bovine serum (F7524, Sigma), 100 units/ml of penicillin, $100 \mu \mathrm{g} / \mathrm{ml}$, streptomycin (P0781, Sigma) and 1\% Glutamax (\#35050087, Life Technologies). For all experiments, cells were incubated in a $5 \% \mathrm{CO}_{2}$ atmosphere at $37^{\circ} \mathrm{C}$.

\section{Chemotherapeutical agents}

Azathioprine, carboplatin, cisplatin, cyclophosphamide, doxorubicin, 5-fluorouracil, gemcitabine, methotrexate, 6-mercaptopurine, mitoxantrone, 6-thioguanine and taxol were used in this study. See Table 1 for details. Untreated and vehicletreated cells were analysed in all experiments.

\section{Sulforhodamine b (SRB) assay}

SRB (S9012, Sigma) measures total biomass by staining cellular proteins. After treatment, cells were fixed in 10\% trichloroacetic acid (T9159, Sigma) for 
$1 \mathrm{~h}$ at $4^{\circ} \mathrm{C}$, stained with SRB (S9012, Sigma) for 15 minutes, and washed 3 times with $1 \%$ acetic acid (27225, Sigma). The incorporated die was solubilised with 10 mM Tris Base, pH 8.8 (T1503, Sigma). Absorbance was spectrophotometrically measured at $562 \mathrm{~nm}$ in a FluoStar Omega plate reader (BMG Labtech). Background measurements were subtracted from all values.

\section{L-lactate assay, $\beta$-hydroxybutyrate assay, glucose consumption}

$1.5 \times 10^{5}$ hTERT-BJ1 cells per well were seeded in a 12 well plate. When cells were attached, drug treatments were added in triplicate for 48 or $72 \mathrm{~h}$. Media was then collected. L-lactate was measured using the L-Lactate Assay Kit (735-10, Trinity Biotech) and $\beta$-hydroxybutyrate ( $\beta$-HB) was determined with the $\beta$-HB Assay Kit (K632, Biovision), according to the manufacturer. L-lactate and $\beta$-HB production were calculated by subtracting the levels of L-lactate or $\beta$-HB in complete media from those in each sample. Glucose concentration was quantified using a FreeStyle Optium Glucose Meter (Abbott). Glucose consumption was calculated by subtracting the levels of glucose in each sample from those in complete media. For all assays, viable cells in each well for each time point were counted using Trypan Blue (T8154, Sigma) and used to normalize all results.

\section{ATP content}

ATP content was measured using CellTiter-Glo (G7570, Promega) and ATP standards (A1852, Sigma). $2 \times$ $10^{4}$ hTERT-BJ1 cells were seeded in black-walled 96 well plates. When cells were attached, drug treatments were added for 24, 48 or $72 \mathrm{~h}$. Six replicates were used for each condition. Media was removed and CellTiter-Glo Assay was performed according to manufacturer's instructions. Light signal was acquired in the Xenogen VivoVision IVIS Lumina (Caliper Life Sciences). Results were normalised by SRB staining. ATP levels were calculated by extrapolating from the standard curve.

\section{Extracellular flux analysis}

Extracellular acidification rate (ECAR) and oxygen consumption rate (OCR) were measured in a XF96 Extracellular Flux Analyzer (Seahorse Biosciences). $1.5 \times$ $10^{4}$ hTERT-BJ1 cells per well were seeded in XF96 plates and incubated with complete medium. When cells were attached, drug treatments were added. Six replicates were run for each condition. After $72 \mathrm{~h}$ of drug treatments, unbuffered DMEM XF medium supplemented with $2 \mathrm{mM}$ glutamine ( $\mathrm{pH} 7.4)$ was added to the cells, and placed in a $37^{\circ} \mathrm{C} \mathrm{CO}_{2}$-free incubator for $1 \mathrm{~h} .10 \mathrm{mM}$ glucose, $1 \mu \mathrm{M}$ oligomycin and $100 \mathrm{mM}$ 2-deoxyglucose (2-DG) were injected into the media at different time points and ECAR was measured (Figure S2A). Likewise, ECAR and OCR were quantified using un-buffered DMEM XF medium supplemented with $2 \mathrm{mM}$ glutamine, $2 \mathrm{mM}$ sodium pyruvate and $10 \mathrm{mM}$ glucose (Figure S2B). Cells were stained with SRB to normalise results. All parameters were calculated according to manufacturer.

\section{Levels of reactive oxygen species, autophagic vesicles and senescence}

For all assays, $1.5 \times 10^{5}$ hTERT-BJ1 cells per well were seeded in 12-well plates. When cells were attached, drug treatments were added for 24,48 or $72 \mathrm{~h}$ in triplicate. Reactive oxygen species (ROS) production was measured using $\mathrm{CM}-\mathrm{H}_{2}$ DCFDA (C6827, Invitrogen). Cells were incubated for $20 \mathrm{~min}$ at $37^{\circ} \mathrm{C}$ with $1 \mu \mathrm{M} \mathrm{CM}-\mathrm{H}_{2} \mathrm{DCFDA}$ diluted in PBS, and then placed in complete media for $20 \mathrm{~min}$ at $37^{\circ} \mathrm{C}$ in the dark, to render the die fluorescent, according to the manufacturer. Autophagy Detection Kit (ab139484, Abcam) was used to detect autophagic vesicle production. Cells were trypsinised and incubated for 30 min at RT in the dark with a solution containing 1:1000 of Green Detection Reagent and 1:1000 of Hoechst in phenol-red free DMEM (D5921, Sigma) supplemented with 5\% FBS, according to the manufacturer. Senescent cells were detected using the fluorescent senescenceassociated $\beta$-galactosidase (SA- $\beta$-gal) activity marker $\mathrm{C}_{12}$ FDG (F1930, Molecular Probes). Cells were trypsinised and incubated with $2 \mathrm{mM}$ of FDG substrate at $37^{\circ} \mathrm{C}$ for 1 minute. Staining was terminated by hypotonic shock by diluting the cells into ice-cold isotonic medium, according to the manufacturer.

ROS signal, autophagy vesicle signal, and SA- $\beta$ gal activity signal were quantified as mean fluorescent intensity of the viable cell population in a BD LSRII flow cytometer (BD Bioscience). Results were analysed using FlowJo software.

\section{Western blotting}

$1 \times 10^{6}$ hTERT-BJ1 fibroblasts were seeded in 10 $\mathrm{cm}$ dishes. When cells were attached, drug treatments were added for $48 \mathrm{~h}$. Cells were lysed in RIPA lysis buffer (R0278, Sigma) containing proteinase inhibitors (05 892970001 , Roche) and kept at $4^{\circ} \mathrm{C}$ for 20 minutes with rotation. Lysates were cleared by centrifugation for 10 minutes at 10,000 xg and supernatants were collected. Equal amounts of protein lysate, as determined by using the BCA protein assay kit (23225, Pierce) were diluted in SDS sample buffer and dry-boiled for 5 minutes before being separated by SDS-PAGE using 4-20\% gels (456-1094, Biorad). Samples were then blotted onto nitrocellulose membranes (170-4159, Biorad), blocked 
in 5\% milk in TBS-Tween 20 (P9416, Sigma) for $1 \mathrm{~h}$ and probed with antibodies against $\alpha$-tubulin (ab4074, Abcam), p-SAPK/JNK (T183-Y185) (4668S, Cell Signalling), P-cJun (S63) (926L1, Cell Signalling), total JNK (9252S, Cell Signalling), total c-Jun (2315S, Cell Signalling), p53 (OP43, Calbiochem), p21 (sc-756, Santa Cruz), and $\alpha$-SMA (sc-53142, Santa Cruz). Bound antibodies were detected using a horseradish peroxidase-conjugated secondary antibody (ab6789 and ab6721, Abcam) and signal was obtained using Supersignal West Pico chemiluminescent substrate (34087, ThermoScientific). Pictures were taken in a ChemiDoc XRS with Image Lab Software (BioRad).

\section{Immunofluorescence}

$1.5 \times 10^{5}$ hTERT-BJ1 fibroblasts per well were seeded in coverslips in 12 well plates. When cells were attached, drug treatments were added for $72 \mathrm{~h}$ in triplicate. Cells were fixed with $2 \%$ paraformaldehyde (28908, Thermo Scientific) in PBS for 20 minutes at RT, permeabilised in $-20^{\circ} \mathrm{C}$-cold methanol for 5 minutes at $4^{\circ} \mathrm{C}$, quenched with $50 \mathrm{mM} \mathrm{NH} 4 \mathrm{Cl}$ in PBS for 10 minutes, rinsed and blocked with IF buffer consisting of 1\% BSA (A3608, Sigma) plus 0.1\% Tween 20 (P9416, Sigma) in PBS for $1 \mathrm{~h}$. Cells were then incubated for $1 \mathrm{~h}$ with the MCT4 primary antibody (sc-50329, Santa Cruz). The fluorescent secondary antibody was added for 30 minutes. Cells were counterstained with DAPI and samples were mounted using Prolong Gold anti-fade reagent (P36934, Invitrogen). Immunofluorescence pictures were taken in a Leica gated Stimulated Emission Depletion Microscopy (gSTED) with additional confocal and multi-photon illumination (room rg106).

\section{Cytokine antibody array}

Cytokine human membrane antibody array (Abcam, ab133998) was used as to screen cytokine secretion $(\mathrm{N}=1)$. $1 \times 10^{6}$ hTERT-BJ1 fibroblasts were seeded in $10 \mathrm{~cm}$ plates until cells were attached and doxorubicin or vehicle were added to the cells for $72 \mathrm{~h}$. Culture media was then placed on the membrane. The dot blot array was developed using Supersignal West Pico chemiluminescent substrate. Pictures were taken in the ChemiDoc XRS with Image Lab Software and ImageJ software was used to quantify the intensity of the dots. Internal membrane loading controls were used to normalise results.

\section{Interleukin 6 ELISA}

Interleukin 6 (IL6) concentration was determined using IL6 Human ELISA Kit (ab100572, Abcam). 3 x $10^{5}$ hTERT-BJ1 fibroblasts were seeded in 6 well plates.
When cells were attached, drug treatments were added for $72 \mathrm{~h}$ in duplicate. Equal amounts of culture media, as determined by using the BCA protein assay kit, were loaded into the ELISA plate and incubated with the antibody overnight at $4^{\circ} \mathrm{C}$ with gentle shaking. Standards and media samples were run in parallel. Absorbance was spectrophotometrically measured at $450 \mathrm{~nm}$ in a FluoStar Omega plate reader (BMG Labtech). Background measurements were subtracted from all values. Finally, IL6 levels were calculated by extrapolating from the standard curve.

\section{Lentivirus infection}

The Cignal Lenti reporter assay (luc) was used to monitor the activity of several signalling pathways in either hTERT-BJ1 fibroblasts or MCF7-GFP cells (see Table 2 for details). Viral particles diluted 1:10 in complete media containing polybrene (sc-134220, Santa Cruz) were added to the cells. Puromycin treatment (P9620, Sigma) was added $48 \mathrm{~h}$ later in order to stably select infected cells.

\section{Luciferase assay}

Luciferase Assay System (E1501, Promega) was performed according to manufacturer's instructions. $2 \times$ $10^{4}$ hTERT-BJ1 fibroblasts were seeded in black-walled 96 well plates. When cells were attached, drug treatments were added for 24, 48 and $72 \mathrm{~h}$. Six replicates were used for each condition. After treatment, Luciferase Assay was performed according to manufacturer's instructions and light signal was acquired in the Xenogen VivoVision IVIS Lumina. Results were normalized by SRB staining. Likewise, $6 \times 10^{3}$ MCF7-GFP cells were seeded in blackwalled 96-well plates as single cultures or in combination with $6 \times 10^{3}$ hTERT-BJ1 fibroblasts. When cells were attached, drug treatments were added for 24 and $48 \mathrm{~h}$ in quadruplicate. After treatment, GFP fluorescence was measured in the plates and Luciferase Assay was performed as before. Results were normalised by GFP fluorescence.

\section{Statistical analyses}

Student's t test was used for statistical comparison of two groups. All data are reported as mean \pm standard deviation of the mean (SEM). All experiments were repeated at least two times with reproducible results. $P$ values lower than 0.05 were considered significant $(* P<$ $0.05, * * P<0.01, * * * P<0.001)$. Microsoft Excel was used to produce all graphs. 


\section{ACKNOWLEDGEMENTS}

We thank Dr. Kang Zeng for confocal microscopy services (Institute of Cancer Sciences), and Mario Pulido for technical assistance. We thank the University of Manchester for providing start-up funds that contributed to the success of this study. In addition, the research laboratories of Professor Lisanti and Dr. Sotgia were supported by funding schemes from the European Union (ERC Advanced Grant), Breakthrough Breast Cancer (BBC), and the Manchester Cancer Research Centre (MCRC).

\section{CONFLICTS OF INTEREST}

The authors disclose no potential conflicts of interest.

\section{AUTHOR CONTRIBUTIONS}

MPP performed all experiments, analysed data and wrote the manuscript; FS and MPL conceived the project and oversaw the studies.

\section{Abbreviations}

AZA, azathioprine; CIS, cisplatin; CP, carboplatin; DOX, doxorubicin; MTX, mitoxantrone; TAX, taxol; CAF, cancer-associated fibroblast; TAM, tumourassociated macrophage; $\beta$-HB, $\beta$-hydroxybutyrate; ECAR, extracellular acidification rate; OCR, oxygen consumption rate; 2-DG, 2-deoxyglucose; MCT4, monocarboxylate transporter 4; SASP, senescence-associated secretory phenotype; IL6, interleukin 6; ROS, reactive oxygen species; SA- $\beta$-gal, senescence-associated- $\beta$-galactosidase; $\alpha \mathrm{SMA}, \alpha$-smooth muscle actin

\section{REFERENCES}

1. Hanahan D and Coussens LM. Accessories to the crime: functions of cells recruited to the tumor microenvironment. Cancer Cell. 2012; 21:309-322.

2. Ronnov-Jessen L and Petersen OW. Induction of alphasmooth muscle actin by transforming growth factor-beta 1 in quiescent human breast gland fibroblasts. Implications for myofibroblast generation in breast neoplasia. Lab Invest. 1993; 68:696-707.

3. Bartling B, Hofmann HS, Silber RE and Simm A. Differential impact of fibroblasts on the efficient cell death of lung cancer cells induced by paclitaxel and cisplatin. Cancer Biol Ther. 2008; 7:1250-1261.

4. Nieman KM, Kenny HA, Penicka CV, Ladanyi A, BuellGutbrod R, Zillhardt MR, Romero IL, Carey MS, Mills GB, Hotamisligil GS, Yamada SD, Peter ME, Gwin K and
Lengyel E. Adipocytes promote ovarian cancer metastasis and provide energy for rapid tumor growth. Nat Med. 2011; 17:1498-1503.

5. Zhang W, Trachootham D, Liu J, Chen G, Pelicano H, Garcia-Prieto C, Lu W, Burger JA, Croce CM, Plunkett W, Keating MJ and Huang P. Stromal control of cystine metabolism promotes cancer cell survival in chronic lymphocytic leukaemia. Nat Cell Biol. 2012; 14:276-286.

6. Martinez-Outschoorn U, Sotgia F and Lisanti MP. Tumor microenvironment and metabolic synergy in breast cancers: critical importance of mitochondrial fuels and function. Seminars in oncology. 2014; 41:195-216.

7. Laberge RM, Awad P, Campisi J and Desprez PY. Epithelial-mesenchymal transition induced by senescent fibroblasts. Cancer Microenviron. 2012; 5:39-44.

8. Martinez-Outschoorn UE, Lin Z, Ko YH, Goldberg AF, Flomenberg N, Wang C, Pavlides S, Pestell RG, Howell A, Sotgia $\mathrm{F}$ and Lisanti MP. Understanding the metabolic basis of drug resistance: therapeutic induction of the Warburg effect kills cancer cells. Cell Cycle. 2011; 10:2521-2528.

9. Porter DC, Farmaki E, Altilia S, Schools GP, West DK, Chen M, Chang BD, Puzyrev AT, Lim CU, Rokow-Kittell R, Friedhoff LT, Papavassiliou AG, Kalurupalle S, Hurteau G, Shi J, Baran PS, et al. Cyclin-dependent kinase 8 mediates chemotherapy-induced tumor-promoting paracrine activities. Proc Natl Acad Sci U S A. 2012; 109:1379913804.

10. Allan JM and Travis LB. Mechanisms of therapy-related carcinogenesis. Nat Rev Cancer. 2005; 5(12):943-955.

11. Boice JD, Jr., Blettner M, Kleinerman RA, Stovall M, Moloney WC, Engholm G, Austin DF, Bosch A, Cookfair DL, Krementz ET and et al. Radiation dose and leukemia risk in patients treated for cancer of the cervix. J Natl Cancer Inst. 1987; 79:1295-1311.

12. Bonuccelli G, Tsirigos A, Whitaker-Menezes D, Pavlides S, Pestell RG, Chiavarina B, Frank PG, Flomenberg N, Howell A, Martinez-Outschoorn UE, Sotgia F and Lisanti MP. Ketones and lactate "fuel" tumor growth and metastasis: Evidence that epithelial cancer cells use oxidative mitochondrial metabolism. Cell Cycle. 2010; 9:3506-3514.

13. Kumari KK and Setty OH. Protective effect of Phyllanthus fraternus against mitochondrial dysfunction induced by co-administration of cisplatin and cyclophosphamide. J Bioenerg Biomembr. 2012; 44:179-188.

14. Velez JM, Miriyala S, Nithipongvanitch R, Noel $T$, Plabplueng CD, Oberley T, Jungsuwadee P, Van Remmen $\mathrm{H}$, Vore $\mathrm{M}$ and St Clair DK. p53 Regulates oxidative stress-mediated retrograde signaling: a novel mechanism for chemotherapy-induced cardiac injury. PLoS One. 2011; 6:e18005.

15. Toullec A, Gerald D, Despouy G, Bourachot B, Cardon M, Lefort S, Richardson M, Rigaill G, Parrini MC, Lucchesi C, Bellanger D, Stern MH, Dubois T, Sastre-Garau X, Delattre 
O, Vincent-Salomon A, et al. Oxidative stress promotes myofibroblast differentiation and tumour spreading. EMBO Mol Med. 2010; 2:211-230.

16. Demaria M, Camporeale A and Poli V. STAT3 and metabolism: how many ways to use a single molecule? Int J Cancer. 2014; 135:1997-2003.

17. Campisi J and d'Adda di Fagagna F. Cellular senescence: when bad things happen to good cells. Nature reviews Molecular cell biology. 2007; 8:729-740.

18. Goehe RW, Di X, Sharma K, Bristol ML, Henderson SC, Valerie K, Rodier F, Davalos AR and Gewirtz DA. The autophagy-senescence connection in chemotherapy: must tumor cells (self) eat before they sleep? J Pharmacol Exp Ther. 2012; 343:763-778.

19. Chang BD, Swift ME, Shen M, Fang J, Broude EV and Roninson IB. Molecular determinants of terminal growth arrest induced in tumor cells by a chemotherapeutic agent. Proc Natl Acad Sci U S A. 2002; 99:389-394.

20. Rodier F, Coppe JP, Patil CK, Hoeijmakers WA, Munoz DP, Raza SR, Freund A, Campeau E, Davalos AR and Campisi J. Persistent DNA damage signalling triggers senescence-associated inflammatory cytokine secretion. Nat Cell Biol. 2009; 11:973-979.

21. Martinez-Outschoorn UE, Whitaker-Menezes D, Lin Z, Flomenberg N, Howell A, Pestell RG, Lisanti MP and Sotgia F. Cytokine production and inflammation drive autophagy in the tumor microenvironment: role of stromal caveolin-1 as a key regulator. Cell Cycle. 2011; 10:17841793.

22. Paunescu V, Bojin FM, Tatu CA, Gavriliuc OI, Rosca A, Gruia AT, Tanasie G, Bunu C, Crisnic D, Gherghiceanu M, Tatu FR, Tatu CS and Vermesan S. Tumour-associated fibroblasts and mesenchymal stem cells: more similarities than differences. J Cell Mol Med. 2011; 15:635-646.

23. Pavlides S, Whitaker-Menezes D, Castello-Cros R, Flomenberg N, Witkiewicz AK, Frank PG, Casimiro MC, Wang C, Fortina P, Addya S, Pestell RG, MartinezOutschoorn UE, Sotgia F and Lisanti MP. The reverse Warburg effect: aerobic glycolysis in cancer associated fibroblasts and the tumor stroma. Cell Cycle. 2009; 8:39844001.

24. Tavares-Valente D, Baltazar F, Moreira R and Queiros $\mathrm{O}$. Cancer cell bioenergetics and $\mathrm{pH}$ regulation influence breast cancer cell resistance to paclitaxel and doxorubicin. J Bioenerg Biomembr. 2013; 45:467-475.

25. Martinez-Outschoorn UE, Prisco M, Ertel A, Tsirigos A, Lin Z, Pavlides S, Wang C, Flomenberg N, Knudsen ES, Howell A, Pestell RG, Sotgia F and Lisanti MP. Ketones and lactate increase cancer cell "stemness," driving recurrence, metastasis and poor clinical outcome in breast cancer: achieving personalized medicine via MetaboloGenomics. Cell Cycle. 2011; 10:1271-1286.

26. Pavlides S, Tsirigos A, Migneco G, Whitaker-Menezes D, Chiavarina B, Flomenberg N, Frank PG, Casimiro MC,
Wang C, Pestell RG, Martinez-Outschoorn UE, Howell A, Sotgia F and Lisanti MP. The autophagic tumor stroma model of cancer: Role of oxidative stress and ketone production in fueling tumor cell metabolism. Cell Cycle. 2010; 9:3485-3505.

27. Chiavarina B, Martinez-Outschoorn UE, WhitakerMenezes D, Howell A, Tanowitz HB, Pestell RG, Sotgia $\mathrm{F}$ and Lisanti MP. Metabolic reprogramming and twocompartment tumor metabolism: opposing role(s) of HIF1alpha and HIF2alpha in tumor-associated fibroblasts and human breast cancer cells. Cell Cycle. 2012; 11:32803289 .

28. Chiavarina B, Whitaker-Menezes D, Migneco G, MartinezOutschoorn UE, Pavlides S, Howell A, Tanowitz HB, Casimiro MC, Wang C, Pestell RG, Grieshaber P, Caro $\mathrm{J}$, Sotgia $\mathrm{F}$ and Lisanti MP. HIF1-alpha functions as a tumor promoter in cancer associated fibroblasts, and as a tumor suppressor in breast cancer cells: Autophagy drives compartment-specific oncogenesis. Cell Cycle. 2010; 9:3534-3551.

29. Guido C, Whitaker-Menezes D, Capparelli C, Balliet R, Lin Z, Pestell RG, Howell A, Aquila S, Ando S, MartinezOutschoorn U, Sotgia F and Lisanti MP. Metabolic reprogramming of cancer-associated fibroblasts by TGFbeta drives tumor growth: connecting TGF-beta signaling with "Warburg-like" cancer metabolism and L-lactate production. Cell Cycle. 2012; 11:3019-3035.

30. Martinez-Outschoorn UE, Lisanti MP and Sotgia F. Catabolic cancer-associated fibroblasts transfer energy and biomass to anabolic cancer cells, fueling tumor growth. Seminars in cancer biology. 2014; 25:47-60.

31. Blobe GC, Schiemann WP and Lodish HF. Role of transforming growth factor beta in human disease. N Engl $\mathrm{J}$ Med. 2000; 342:1350-1358.

32. Ng IH, Yeap YY, Ong LS, Jans DA and Bogoyevitch MA. Oxidative stress impairs multiple regulatory events to drive persistent cytokine-stimulated STAT3 phosphorylation. Biochimica et biophysica acta. 2014; 1843:483-494.

33. Boyd NF, Rommens JM, Vogt K, Lee V, Hopper JL, Yaffe MJ and Paterson AD. Mammographic breast density as an intermediate phenotype for breast cancer. The Lancet Oncology. 2005; 6:798-808

34. Capparelli C, Chiavarina B, Whitaker-Menezes D, Pestell TG, Pestell RG, Hulit J, Ando S, Howell A, MartinezOutschoorn UE, Sotgia F and Lisanti MP. CDK inhibitors (p16/p19/p21) induce senescence and autophagy in cancerassociated fibroblasts, "fueling" tumor growth via paracrine interactions, without an increase in neo-angiogenesis. Cell Cycle. 2012; 11:3599-3610.

35. Capparelli C, Guido C, Whitaker-Menezes D, Bonuccelli G, Balliet R, Pestell TG, Goldberg AF, Pestell RG, Howell A, Sneddon S, Birbe R, Tsirigos A, Martinez-Outschoorn U, Sotgia F and Lisanti MP. Autophagy and senescence in cancer-associated fibroblasts metabolically supports tumor growth and metastasis via glycolysis and ketone production. 
Cell Cycle. 2012; 11:2285-2302.

36. Martinez-Outschoorn UE, Lin Z, Whitaker-Menezes D, Howell A, Lisanti MP and Sotgia F. Ketone bodies and twocompartment tumor metabolism: stromal ketone production fuels mitochondrial biogenesis in epithelial cancer cells. Cell Cycle. 2012; 11:3956-3963.

37. Yeo SG, Kim DY, Kim KH, Ku JL, Kim JS, Cho MJ, Kim ES and Yoo BC. Hydroxymethylglutaryl-coenzyme a synthase 2 expression is associated with chemoradiotherapy responses in colorectal cancer. Diseases of the colon and rectum. 2012; 55:686-694.

38. Andre T, Meuleman N, Stamatopoulos B, De Bruyn C, Pieters K, Bron D and Lagneaux L. Evidences of early senescence in multiple myeloma bone marrow mesenchymal stromal cells. PLoS One. 2013; 8:e59756.

39. Mulligan HD, Beck SA and Tisdale MJ. Lipid metabolism in cancer cachexia. Br J Cancer. 1992; 66:57-61.

40. Kamp DW, Shacter E and Weitzman SA. Chronic inflammation and cancer: the role of the mitochondria. Oncology. 2011; 25:400-410, 413.

41. Shacter E and Weitzman SA. Chronic inflammation and cancer. Oncology. 2002; 16(2):217-226, 229; discussion 230-212

42. Mantovani A, Allavena P, Sica A and Balkwill F. Cancerrelated inflammation. Nature. 2008; 454:436-444.

43. Oshima $\mathrm{H}$ and Oshima $\mathrm{M}$. The inflammatory network in the gastrointestinal tumor microenvironment: lessons from mouse models. Journal of gastroenterology. 2012; 47:97106.

44. Al-Dasooqi N, Gibson RJ, Bowen JM and Keefe DM. Matrix metalloproteinases: key regulators in the pathogenesis of chemotherapy-induced mucositis? Cancer chemotherapy and pharmacology. 2009; 64:1-9.

45. Torres MA, Pace TW, Liu T, Felger JC, Mister D, Doho GH, Kohn JN, Barsevick AM, Long Q and Miller AH. Predictors of depression in breast cancer patients treated with radiation: role of prior chemotherapy and nuclear factor kappa B. Cancer. 2013; 119:1951-1959.

46. Briscoe $\mathrm{J}$ and Therond PP. The mechanisms of Hedgehog signalling and its roles in development and disease. Nature reviews Molecular cell biology. 2013; 14:416-429.

47. Spitzner M, Ebner R, Wolff HA, Ghadimi BM, Wienands J and Grade M. STAT3: A Novel Molecular Mediator of Resistance to Chemoradiotherapy. Cancers. 2014; 6:19862011.

48. Kahn M. Can we safely target the WNT pathway? Nature reviews Drug discovery. 2014; 13:513-532.

49. Teglund $\mathrm{S}$ and Toftgard R. Hedgehog beyond medulloblastoma and basal cell carcinoma. Biochimica et biophysica acta. 2010; 1805:181-208.

50. Javelaud D, Pierrat MJ and Mauviel A. Crosstalk between TGF-beta and hedgehog signaling in cancer. FEBS letters. 2012; 586:2016-2025.

51. Harris LG, Samant RS and Shevde LA. Hedgehog signaling: networking to nurture a promalignant tumor microenvironment. Molecular cancer research : MCR. 2011; 9:1165-1174.

52. Zhang Q, Raje V, Yakovlev VA, Yacoub A, Szczepanek K, Meier J, Derecka M, Chen Q, Hu Y, Sisler J, Hamed H, Lesnefsky EJ, Valerie K, Dent P and Larner AC. Mitochondrial localized Stat3 promotes breast cancer growth via phosphorylation of serine 727 . J Biol Chem. 2013; 288:31280-31288.

53. Sherwood V, Chaurasiya SK, Ekstrom EJ, Guilmain W, Liu Q, Koeck T, Brown K, Hansson K, Agnarsdottir M, Bergqvist M, Jirstrom K, Ponten F, James P and Andersson T. WNT5A-mediated beta-catenin-independent signalling is a novel regulator of cancer cell metabolism. Carcinogenesis. 2014; 35:784-794.

54. Zhang DD. The Nrf2-Keap1-ARE signaling pathway: The regulation and dual function of Nrf2 in cancer. Antioxid Redox Signal. 2010; 13:1623-1626.

55. No JH, Kim YB and Song YS. Targeting nrf2 signaling to combat chemoresistance. Journal of cancer prevention. 2014; 19:111-117.

56. DeNardo DG, Brennan DJ, Rexhepaj E, Ruffell B, Shiao SL, Madden SF, Gallagher WM, Wadhwani N, Keil SD, Junaid SA, Rugo HS, Hwang ES, Jirstrom K, West BL and Coussens LM. Leukocyte complexity predicts breast cancer survival and functionally regulates response to chemotherapy. Cancer discovery. 2011; 1:54-67.

57. Nakasone ES, Askautrud HA, Kees T, Park JH, Plaks V, Ewald AJ, Fein M, Rasch MG, Tan YX, Qiu J, Park J, Sinha P, Bissell MJ, Frengen E, Werb Z and Egeblad M. Imaging tumor-stroma interactions during chemotherapy reveals contributions of the microenvironment to resistance. Cancer Cell. 2012; 21:488-503.

58. Tye H, Kennedy CL, Najdovska M, McLeod L, McCormack W, Hughes N, Dev A, Sievert W, Ooi CH, Ishikawa TO, Oshima H, Bhathal PS, Parker AE, Oshima M, Tan P and Jenkins BJ. STAT3-driven upregulation of TLR2 promotes gastric tumorigenesis independent of tumor inflammation. Cancer Cell. 2012; 22:466-478.

59. Tymoszuk P, Charoentong P, Hackl H, Spilka R, MullerHolzner E, Trajanoski Z, Obrist P, Revillion F, Peyrat JP, Fiegl H and Doppler W. High STAT1 mRNA levels but not its tyrosine phosphorylation are associated with macrophage infiltration and bad prognosis in breast cancer. BMC cancer. $2014 ; 14: 257$. 